\title{
El homicidio imprudente agravado por la embriaguez o el influjo de sustancias que produzcan dependencia física o psíquica*
}

\author{
Juan Oberto Sotomayor Acosta** \\ Juan Carlos Alvarez Alvarez ${ }^{*}$
}

\section{Resumen}

La primera parte del artículo presenta un panorama general sobre los problemas discutidos en la doctrina nacional colombiana en relación con el homicidio agravado por la embriaguez o por el influjo de sustancias que producen dependencia física 0 psíquica, en especial los problemas relativos al fundamento de la agravación de la sanción penal para estos casos. También se analizan algunas decisiones de la Corte Constitucional en relación con el mismo tema. La segunda parte se dedica a explicar las dificultades de interpretación que surgen a partir de la entrada en vigencia de la ley 1696 de 2013, que modifica la regulación del homicidio imprudente. Allí se explican las diferencias y los problemas de igualdad de trato que se presentan a raíz de la coexistencia de los numerales 1 y 6 del art. 110 C.P., utilizando para ello el test de proporcionalidad.

\footnotetext{
* Este trabajo se realizó en el marco del proyecto "Las garantías penales como límite y guía en la solución de problemas penales complejos" (DER2013-47511-R), que se desarrolla en colaboración con la Universidad de León, bajo la dirección del profesor Miguel Díaz y García-Conlledo. En el mismo colaboró como auxiliar Santiago Ramírez Jaramillo, estudiante de Derecho de la Universidad EAFIT y destacado alumno del semillero de derecho penal.

* Profesores de derecho penal, Universidad EAFIT (Medellín, Colombia).
} 


\section{Palabras clave}

Homicidio imprudente, embriaguez, Ley 1696 of 2013, circunstancias de agravación, test de proporcionalidad.

\section{Abstract}

The first section of this article presents an overview on the problems discussed by Colombian legal scholars in relation to the crime of involuntary manslaughter aggravated by inebriation or the influence of substances that produce physical or psychological dependence, and particularly problems related to the grounds for aggravating circumstances in these events. Some opinions of the Colombian Constitutional Court are also analyzed in this section. The second part of the article aims to explain the hermeneutical difficulties that have arisen since the entry into force of Law 1696 of 2013, which modifies the regulation of involuntary manslaughter. The differences and equal treatment problems that present themselves as a result of the coexistence of sub-paragraphs 1 and 6 of article 110 of the Colombian Criminal Code are explained in this section by employing the proportionality test.

\section{Keywords}

Involuntary manslaughter, driving while intoxicated, Law 1696 of 2013, aggravating circumstances, proportionality test.

\section{Sumario}

I. Introducción. II. Los problemas de la circunstancia agravante de la embriaguez desde el C.P. de 1980 hasta la entrada en vigencia de la ley 1696 de 2013. a. Las discusiones de la doctrina colombiana sobre el fundamento de la circunstancia del art. 330-1, en vigencia del C.P. de 1980; $b$. Las críticas a los fundamentos de la circunstancia planteados por la doctrina en vigencia del código penal de 1980. c. El punto de vista de la Corte Constitucional sobre el fundamento de la agravante en la sentencia C-425 de 1997; d. La regulación de la circunstancia en vigencia de la ley 599 de 2000 y la sentencia C-115 de 2008; III. Los problemas constitucionales que se derivan del tratamiento punitivo diferenciado de la circunstancia de la embriaguez a partir de la ley 1696 de 2013. a. El tratamiento jurídico-penal diferenciado de la embriaguez en el homicidio culposo (núms. 1 y 6 del art. 110 C.P.) conforme a las exigencias del derecho constitucional a la igualdad (arts. 13 Const. Pol. y 7 C.P.); $b$. La circunstancia agravante del núm. 6 del art. 110 C.P. (introducida por la ley 1696 de 2013): una medida desproporcionada y por tanto inconstitucional. 
130 El homicidio imprudente agravado por la embriaguez o el influjo de sustancias que produzcan dependencia física o psíquica - Juan Oberto Sotomayor Acosta y Juan Carlos Álvarez Álvarez

\section{Introducción}

La primera parte de este trabajo se ocupará de presentar una panorámica general sobre algunos problemas discutidos en la doctrina nacional y en algunas decisiones de la Corte Constitucional colombiana en relación con el homicidio agravado por la embriaguez o por el influjo de sustancias que producen dependencia física o psíquica a partir del código penal de 1980. La segunda parte se centrará en explicar los problemas interpretativos y las alternativas de solución que a los mismos se proponen, surgidos a raíz de la entrada en vigencia de la ley 1696 de 2013, la cual, entre otros aspectos, modificó el artículo 110 de la ley 599 de 2000 (código penal vigente).

En ese orden de ideas, en el primer apartado se hará un esbozo de las discusiones y críticas de la doctrina colombiana sobre el fundamento de la circunstancia del artículo 330 numeral 1 del código penal de 1980 (Decreto ley 100 de 1980), así mismo se presentará y analizará los puntos de vista de la Corte Constitucional sobre el fundamento de la circunstancia agravante de la embriaguez, expresados en las sentencias C-425 de 1997 y C-115 de 2008.

En el segundo apartado se explican las diferencias y los problemas de igualdad de trato que se presentan a raíz de la coexistencia de los numerales 1 y 6 del art. 110 C.P. Así mismo, se hace un análisis desde la perspectiva del principio de proporcionalidad tendiente a establecer si la diferencia de trato que se deriva de la aplicación de las circunstancias de agravación ya indicadas, estaría o no justificado, llegándose a la conclusión, por las razones que en el lugar correspondiente se explican de manera amplia, que tal diferenciación en el tratamiento penal del homicidio imprudente no parece compatible con la Constitución Política colombiana.

\section{Los problemas de la circunstancia agravante de la embriaguez desde el C.P. de 1980 hasta la entrada en vigencia de la ley 1696 de 2013.}

a. Las discusiones de la doctrina colombiana sobre el fundamento de la circunstancia del art. 330-1, en vigencia del C.P. de 1980.

El artículo 330 numeral 1 C.P. de 1980 estableció una circunstancia de agravación del homicidio imprudente para aquellos eventos en los que el sujeto al momento de cometer el hecho "se encontraba bajo el influjo de bebida embriagante o de droga 0 sustancia que produzca dependencia física o síquica". 
Esta circunstancia agravante del delito de homicidio imprudente dio lugar a importantes debates en la doctrina nacional y a pronunciamientos de la Corte Constitucional sobre algunos de los problemas discutidos por la doctrina. Los asuntos discutidos estaban relacionados, principalmente, con la justificación de la circunstancia de agravación. Las razones ofrecidas por los autores nacionales con miras a fundamentar un tratamiento punitivo más severo del homicidio imprudente realizado en las condiciones previstas en el artículo 330 numeral 1, se pueden agrupar, básicamente, en dos: las asociadas a necesidades de prevención general por un lado y las relacionadas con criterios de injusto y de culpabilidad, por el otro'.

Las justificaciones de prevención general se deducen de las alusiones que se hacían a la necesidad de motivar a los ciudadanos para que se abstuvieran de conducir bajo el influjo de bebidas embriagantes o de sustancias estupefacientes, por ser comportamientos considerados altamente peligrosos, consideraciones que en general se encontraban referidas a supuestos de homicidio imprudente en accidentes de tránsito².

Molina Arrubla y Gómez López se destacan en esta línea de argumentación. En efecto, para el primero, la agravación apunta "a exigir que los coasociados guarden el mayor cuidado y diligencia en sus actuaciones personales, de tal manera que tengan siempre dispuestos sus cinco sentidos, a fin de no ocasionar daño a los demás" ${ }^{3}$. Mientras que para el segundo, la circunstancia tiene como fundamento el hecho de que "la mayor parte de los accidentes de tránsito se cometen bajo el influjo de bebidas embriagantes o de sustancias que producen dependencia física o psíquica, las cuales el autor sabía enervan o menguan el normal funcionamiento

1 Al respecto, Sotomayor Acosta, Juan Oberto y Gallego García, Gloria María, "Las circunstancias agravantes del homicidio imprudente en el Código penal colombiano", en Nuevo Foro Penal, No. 61, Bogotá, 1999, p. 40. Véase también, aunque ya en relación con el C.P. de 2000, a TAmaYo Patiño, Francisco Javier, "Las circunstancias de agravación punitiva en el derecho penal colombiano. Aproximaciones a una fundamentación", en Nuevo Foro Penal, No. 79, Medellín, 2012, pp. 48-49.

2 Así, por ejemplo, Gómez López, Jesús Orlando, El homicidio, tomo Il, Bogotá, Temis, 1997, p. 63: “Como efectivamente se advirtió en el seno de la comisión, son los delitos culposos cometidos en medio de vehículos automotores los más abundantes y que más vidas cuestan por su corriente producción". Sin embargo, en la alusión que se hacen a los accidentes de tránsito no se hace referencia a estudios estadísticos que demuestren que la mayoría de ellos tiene como causa la embriaguez del conductor. Aunque no se pudo acceder a información de la época, en informes más recientes elaborados por el Instituto Nacional de Medicina Legal y Ciencias Forenses, por lo menos hoy en día, no parece tan claro que la mayoría de los accidentes de tránsito se deban a la embriaguez, véase Forensis. Datos para la vida, Vol. 14, No. 1, Bogotá, 2013.

3 Molina Arrubla, Carlos Mario, Delitos contra la vida y la integridad personal, Medellín, Diké, 1995, p. 293. 
de las capacidades psíquicas del hombre..."4. De los anteriores planteamientos puede deducirse que la justificación de la circunstancia agravante estaría dada por la necesidad de motivar a los ciudadanos para que se abstengan de realizar ciertas actividades peligrosas bajo el influjo del alcohol o de sustancias que produzcan dependencia física o psíquica.

Un aspecto adicional en el planteamiento de Molina Arrubla, esta vez referido al injusto, es el relativo al nexo de determinación. Según este autor: "Si a partir de la ingestión o administración de una substancia de aquellas que, genéricamente, producen dependencia física o psíquica, se llega a la materialización de un 'homicidio culposo', habrá que colegir que, precisamente, la afectación en los sentidos normales de la persona ocasionó tal substancia, es la determinante del resultado dañoso (...). Mientras no exista tal 'nexo causal' entre la ingestión de la sustancia que crea adicción, y la causación del resultado dañoso, lo primero será penalmente irrelevante" ${ }^{\prime \prime}$.

Otra línea de argumentación es la seguida por Gómez Méndez quien acude tanto a criterios de injusto como de culpabilidad para justificar la mayor punibilidad del homicidio imprudente ${ }^{6}$ en las condiciones previstas en el artículo 330, numeral 1. Los criterios relativos a un mayor injusto se pueden apreciar en el siguiente planteamiento del citado autor:

“la primera circunstancia tiene que ver con una especial situación del sujeto activo al momento de la realización de hecho punible. Es obvio que esa omisión del deber de cuidado es mayor cuando el agente voluntariamente ha alterado su organismo en condiciones que disminuyen su capacidad de previsión, los reflejos, las posibilidades de actuar etc. Se comprende aquí el alcohol, la marihuana, la morfina, la cocaína, la heroína $y$, en general, todas las llamadas sustancias estupefacientes. En todos estos casos es mayor, así mismo el riesgo para la sociedad. Un individuo que conduce un vehículo bajo los efectos de la marihuana, por ejemplo, está en mayor probabilidad de causar un homicidio o lesiones que un individuo "en condiciones normales". El fundamento para la imposición de pena no es propiamente el hecho de la ingestión misma de la bebida o la

4 Gómez López, Jesús Orlando, El Homicidio, p. 63.

5 Molina Arrubla, Carlos Mario, Delitos contra la vida y la integridad personal, p. 293; en igual sentido, la Corte Suprema de Justicia, Sentencia del 8 de junio de 1995 (M.P.: F. Arboleda Ripoll), en Gaceta Judicial, No. 2475, vol. 11, Bogotá, 1995.

6 En esos términos lo ponen de presente Sotomayor Acosta y Gallego García, "Las circunstancias agravantes", p. 41. 
sustancia estupefaciente, sino la falta de previsión por parte del agente que dentro de tales condiciones personales se acreciente la posibilidad de causar daño"7.

En este planteamiento subyace la idea de una especie de "mayor desvalor de acción", en la medida que afirma que "en todos estos casos es mayor, así mismo el riesgo para la sociedad", de lo cual puede colegirse que el fundamento de la agravación radicaría en un mayor injusto por tratarse de una conducta ex ante más peligrosa.

Como ya se dijo, Gómez Méndez también acude a criterios relacionados con una mayor culpabilidad para fundamentar la circunstancia que venimos comentando, y ello se advierte en la afirmación según la cual el hecho es más grave en tanto "el agente ha alterado su organismo en condiciones que disminuyen su capacidad de previsión, los reflejos, las posibilidades de actuar, entre otros." ${ }^{8}$.

b. Las críticas a los fundamentos de la circunstancia planteados por la doctrina en vigencia del código penal de $1980^{9}$.

Sobre las presuntas necesidades de prevención que servirían de fundamento para justificar una sanción más grave para el homicidio imprudente realizado en las condiciones previstas en el art. 330-1, se dijo que las mismas, al no estar referidas a la mayor gravedad del hecho (injusto) o la mayor culpabilidad del sujeto, no podrían fundamentar por sí mismas una mayor punibilidad del homicidio culposo. En efecto, las razones preventivo generales pueden perfectamente ser atendibles como criterios para fundamentar la punición de la imprudencia. Es decir, la necesidad de motivar a los ciudadanos para que en la realización de ciertas actividades observen el cuidado jurídicamente exigido - deber objetivo de cuidado- con el fin de evitar la lesión o el peligro para los bienes jurídicos, es lo que da fundamento a cualquier injusto imprudente, llámese homicidio, peculado contaminación ambiental, etc. y por tanto, tales razones preventivas no pueden luego, por sí solas, justificar la agravación de un delito, si en ese caso específico no se puede demostrar un mayor injusto o una mayor culpabilidad.

7 Gómez Méndez, Alfonso, Delitos contra la vida y la integridad personal, Bogotá, Universidad Externado de Colombia, 1998, pp. 264-265.

8 Gómez Méndez, Alfonso, Delitos contra la vida y la integridad personal, pp. 264-265. Sobre esta afirmación del autor véanse los comentarios de Sotomayor Acosta y Gallego García, "Las circunstancias agravantes", p. 43.

9 En este punto se siguen, en general, las críticas realizadas por Sotomayor Acosta, Juan Oberto y Gallego García, Gloria María, "Las circunstancias agravantes", pp. 41-45. 
En cuanto a los fundamentos relativos al injusto, se criticó el hecho de que la embriaguez por sí misma no implica un mayor peligro para la vida, o por lo menos no un mayor peligro que el que supondría por ejemplo conducir en contravía, o con gran exceso de velocidad, o un vehículo con graves deficiencias en el sistema de frenado, o realizar una intervención quirúrgica sin haber realizado previamente la asepsia al instrumental etc., con lo cual, además, se evidenciaba la desigualdad de trato al agravar el homicidio únicamente en los eventos de embriaguez, bajo el supuesto, indemostrado, de que el ponerse en esa condición, significaba una más grave violación al deber objetivo de cuidado.

La anterior objeción estaba dirigida principalmente a la idea planteada por Gómez Méndez, según la cual "es obvio que esa omisión del deber de cuidado es mayor cuando el agente voluntariamente ha alterado su organismo en condiciones que disminuyen su capacidad de previsión, los reflejos, las posibilidades de actuar", conforme a lo ya explicado no resulta tan "obvio" que la embriaguez suponga una mayor violación del deber de cuidado, que la que supone por ejemplo, cruzarse un semáforo en rojo en un sitio de alta circulación vehicular y peatonal.

Además, se puso también de presente que quien realiza una determinada actividad peligrosa en estado de embriaguez o bajo el influjo de sustancias que producen dependencia física o psíquica no está haciendo nada distinto que violar el mínimo cuidado debido que en estos casos consiste en estar en condiciones físicas y psíquicas óptimas que aminoren los riesgos que ya, de suyo, supone realizar ciertas actividades que si bien, están permitidas, su ejecución está condicionada a la observancia de unos deberes de cuidado, cuya infracción fundamenta el injusto en todos los delitos imprudentes. Así las cosas, también parecía claro que la agravante del numeral 1 del artículo 330 partía de desvalorar el mismo hecho que ya se había tenido en cuenta para fundamentar el hecho imprudente, esto es, la violación del deber de cuidado que en el caso concreto, consistía en realizar la actividad bajo el estado de embriaguez.

Tal forma de razonar dejaba de lado la consideración de que la infracción al deber objetivo de cuidado es un elemento propio de la estructura de todos los delitos imprudentes y por tanto, es fundamento del injusto básico, en este caso de homicidio imprudente. Por tanto resultaba incorrecto que también se utilizara como criterio para justificar la agravación, en la medida en que ello implicaba una violación del non bis in idem ${ }^{10}$.

10 Cfr. Sotomayor Acosta, Juan Oberto y Gallego García, Gloria María, "Las circunstancias agravantes", p. 45. 
De otra parte, la alusión de Molina Arrubla al nexo de determinación ${ }^{11}$ como requisito para que pueda aplicarse la agravante fue también objeto de crítica, por cuanto tal nexo es un elemento propio de la estructura del tipo básico en los delitos imprudentes, según el cual, para que pueda predicarse la tipicidad del hecho a título de imprudencia, es indispensable que en cada caso se constate que la inobservancia del deber de cuidado fue determinante del resultado lesivo. En consecuencia, afirmar que la agravante se aplica en la medida en que el haber actuado en las condiciones previstas en el art. 330 numeral 1 haya sido determinante en el resultado, no sirve tampoco para fundamentar la mayor gravedad del homicidio imprudente, puesto que la existencia misma del delito presupone que se constate el nexo entre la violación del deber de cuidado - por ejemplo conducir embriagadoy el resultado muerte. En otras palabras, si no hay nexo de determinación entre la concreta violación del deber de cuidado - por ejemplo la conducción bajo el estado de embriaguez- y el resultado no habrá delito imprudente, o por lo menos no será atribuible al estado de embriaguez.

Dicho lo anterior, resulta fácil concluir que la exigencia del nexo de determinación entre la embriaguez o el influjo de sustancias que producen dependencia física o psíquica y el resultado, no resulta idóneo para explicar por qué, por ejemplo, resultaría más grave que un conductor ebrio provoque la muerte de un peatón a que un conductor sobrio y en pleno usos de sus facultades mentales, por cruzar un semáforo en rojo, mate también a un peatón. Es claro que en ambos casos para que pueda tipificarse el homicidio imprudente se requiere que se constate el nexo de determinación entre la violación del deber de cuidado -conducir en estado de ebriedad o pasar el semáforo en rojo- y el resultado muerte del peatón.

Acerca de los argumentos de Gómez Méndez ${ }^{12}$ relativos a una mayor culpabilidad del autor, se puso en evidencia la contradicción valorativa que implicaba el hecho de que en muchas ocasiones la embriaguez fuese reconocida como una circunstancia que da lugar a una menor culpabilidad del sujeto, e incluso, en algunos casos a su exclusión ${ }^{13}$. En efecto, si la embriaguez o el efecto que producen ciertas sustancias consiste en disminuir la capacidad de previsión del sujeto, sus reflejos y su posibilidades de actuar, parece entonces incuestionable que en tales circunstancias

11 Véase Molina Arrubla, Carlos Mario, Delitos contra la vida y la integridad personal, p. 293. No obstante el autor incurre en la imprecisión de llamarlo "nexo causal".

12 Gómez Méndez, Alfonso, Delitos contra la vida y la integridad personal, pp. 264-265.

13 Al respecto véase a Agudelo Betancur, Nódier, Embriaguez y responsabilidad penal, Medellín, Nuevo Foro, 2012. 
se reconozca que la persona ha actuado con una menor capacidad de motivarse y dirigir su comportamiento conforme a las exigencias del ordenamiento jurídico, es decir, con un menor grado de culpabilidad.

Adicionalmente, de los planteamientos de Gómez Méndez cabe destacar su afirmación en el sentido de que el hecho se considera más grave en la medida en que el agente "ha alterado voluntariamente su organismo en condiciones que disminuyen su capacidad de previsión, los reflejos, las posibilidades de actuar, entre otros." ${ }^{14}$. La referencia a la alteración voluntaria de su organismo por parte del sujeto activo del delito, se ha dicho que lo que en realidad está planteando es un supuesto de actio libera in causa ${ }^{15}$, puesto que lo que se estaría reprochando en forma más severa no es el hecho de la embriaguez por sí misma, sino el que el sujeto haya decidido voluntariamente, en un momento previo, ponerse en esa condición. Esa vía de argumentación en consecuencia, tampoco explica en forma satisfactoria el fundamento de la agravante.

c. El punto de vista de la Corte Constitucional sobre el fundamento de la agravante en la sentencia C-425 de 1997.

El artículo 397 del decreto 2700 de 1991 estableció la posibilidad de la detención preventiva para los delitos de lesiones culposas previstas en los artículos 333, 334, 335 y 336 del Código Penal, "cuando el sindicado en el momento de la realización del hecho se encuentre en estado de embriaguez aguda o bajo el influjo de droga o sustancia que produzca dependencia física o síquica, demostrado por dictamen técnico o por un método paraclínico, o abandone sin justa causa el lugar de la comisión del hecho".

Con ocasión de una demanda de inconstitucionalidad parcial del citado artículo 397, la Corte Constitucional en la sentencia C-495 de 1997, explicó entre otros aspectos, las razones por las cuales según su criterio la agravación del delito de lesiones culposas resultaba ajustada a la Constitución Política. Los argumentos plateados por la citada corporación sobre el tema específico de la agravación por haber el sujeto actuado bajo el efecto del alcohol o de sustancias estupefacientes, están contenidas en el siguiente párrafo de la sentencia:

14 Véase Gómez Méndez, Alfonso, Delitos contra la vida, p. 264-265 (cursiva fuera del original).

15 Sobre las actio libera in causa, con referencias a la legislación colombiana, véase Araque Moreno, Diego, "Consideraciones sobre la actio libera in causa", en Nuevo Foro Penal, núm. 66, Medellín, Universidad EAFIT, 2003, pp. 157-198. 
"...ni el incremento punitivo ni la causal de detención preventiva tienen fundamento en el propósito de formular un reproche a la persona por el hecho mismo de la ingestión de bebidas alcohólicas o de sustancias estupefacientes, sino que reparan en la falta de previsión de quienes, por las alteraciones que se producen en su organismo, están llamados a observar una conducta más cuidadosa, cuya desatención constituye una violación al riesgo permitido, que justifica la detención preventiva, pues tales circunstancias de una parte, agravan objetivamente el hecho y, de otra parte, incrementan la punibilidad, factor este último que acrecienta las posibilidades de fuga del imputado" (cursivas fuera del original).

Dado que el problema principal del que se ocupa la Corte Constitucional en la sentencia referida tiene que ver con los requisitos que según el demandante debían tenerse en cuenta al momento de valorar la procedecencia la medida de aseguramiento de detención preventiva, la alusión que se hace en la parte considerativa de la sentencia al fundamento de la agravación de las lesiones culposas en estado de embriaguez o bajo el efecto de sustancias que producen dependencia física o psíquica es solo tangencial, y está consignado en el párrafo transcrito. No obstante vale la pena tenerlo en cuenta porque refleja de manera muy precisa la idea que la Corte Constitucional tiene de esta agravante y que coincide con los planteamientos de algunos sectores de la doctrina nacional acerca de su fundamento.

Como se puede advertir, la Corte Constitucional se vale de dos criterios para considerar justificado el "incremento punitivo". Por un lado, la referencia a la falta de previsión que supone actuar en estado de embriaguez o bajo el efecto de aquellas otras sustancias, cuya desatención constituye una violación al riesgo permitido, coincide con la idea de aquel sector de la doctrina que considera que actuar en estado de embriaguez o bajo el influjo de sustancias que producen dependencia física o psíquica implica una violación al deber objetivo de cuidado y por tanto, al desatender esos deberes de cuidado se está actuando por fuera del riesgo permitido. En ese sentido las críticas ya formuladas sobre este particular cabe reiterarlas en idénticos términos al planteamiento de la Corte Constitucional.

En lo que respecta a la consideración según la cual tales circunstancias "agravan objetivamente el hecho" es coincidente con la idea también expuesta en la doctrina colombiana relativa a un mayor injusto. Sin embargo, cabe precisar que la Corte no explica las razones por las cuales considera que el hecho es "objetivamente más grave", pero también cabe suponer por el contexto en el que hace la afirmación, que se refiere a una mayor peligrosidad ex ante de la conducta de quien actúa bajo 
los efectos de las mencionadas sustancias. Acá de nuevo, podemos remitir a las objeciones que en relación con esta línea argumentativa se han dejado expuestas más arriba, en el sentido de que ello implica una doble desvaloración de la embriaguez o el consumo de sustancias sicoactivas: como elemento constitutivo de la infracción al deber objetivo de cuidado y como circunstancia agravante.

d. La regulación de la circunstancia en vigencia de la ley 599 de 2000 y la sentencia C-115 de 2008.

La ley 599 de 2000 mediante la cual se expidió un nuevo código penal y derogó el decreto ley 100 de 1980 reprodujo en forma muy similar al código anterior la circunstancia de agravación a la que nos hemos venido refiriendo, así:

"Artículo 110. (...) 1. Si al momento de cometer el hecho el agente se encontraba bajo el influjo de bebida embriagante o de droga o sustancia que produzca dependencia física 0 síquica y ello haya sido determinante para su ocurrencia".

Como puede observarse la única novedad de esta disposición consistió en agregar la exigencia de que el estado de embriaguez o el influjo de sustancias que produzcan dependencia física o psíquica hubiese sido determinante para el resultado, con lo cual en realidad no se agregó nada nuevo que pudiera aportar elementos para una fundamentación distinta de la agravante. Así las cosas, las discusiones y críticas a la fundamentación que en vigencia del código de 2000 se pudieron haber presentado son en esencia las mismas que en vigencia del código de 1980.

Sin embargo, un hito importante en esa discusión lo marcó la sentencia C-115 de 2008, toda vez que en esta providencia la Corte Constitucional se pronunció de fondo sobre algunos de los aspectos debatidos por la doctrina, en especial el relacionado con la violación del non bis in ídem que según algunos implicaba la mencionada circunstancia de agravación.

La Corte Constitucional zanjó la discusión planteada por la doctrina sobre la violación del non bis in ídem señalando que de la aplicación de la circunstancia no se podía derivar una vulneración de la prohibición de juzgar dos veces el mismo hecho, para lo cual expuso los siguientes argumentos:

"Debe puntualizarse que la sanción se presenta cuando 'por culpa' del agente se produce un resultado (muerte o lesión, según el caso), que se agrava punitivamente por haber sido determinante para su ocurrencia el consumo de bebidas alcohólicas, drogas 0 sicotrópicos, que afectaron el funcionamiento de su organismo, particularmente en sus facultades de observación, control y reacción, sin que el sólo hecho de consumir esa clase de sustancias conlleve, por sí mismo, la comisión de un delito. 
“Contrario a lo expuesto por el demandante, la circunstancia específica de agravación punitiva contenida en el numeral $1^{0}$ del artículo 110 de la Ley 599 de 2000, sólo tendrá lugar si al "cometer la conducta" el agente se encontraba bajo el influjo de tales sustancias, y ello "haya sido determinante" para la producción del resultado lesivo.

"Tiene que ser determinante, no basta solo con estar embriagado para satisfacer los presupuestos que dan cabida al agravante, si no tiene relación con el resultado no puede ser agravado y por eso no hay una violación al principio de non bis in ídem".

En la misma providencia la Corte Constitucional agregó:

"Entonces, cuando el legislador en el ejercicio de su facultad y deber de regular el ius puniendi del Estado, incluyó como una de las circunstancias de agravación punitiva la determinación, en la producción del resultado lesivo, de la ingestión de sustancias que alteren la capacidad sicomotora, no se presenta una segunda punición del mismo comportamiento, como plantea el actor...

"Y, como se desprende del citado desarrollo jurisprudencial de la Sala de Casación Penal, para tal efecto compete al operador judicial establecer, 'ex ante' al acto imputado, si el consumo de esas sustancias fue determinante en la producción del riesgo, pues no es suficiente que el agente esté bajo su efecto al momento de cometer la conducta punible. Si no tiene relación con el resultado causado no hay lugar a la agravación de la pena y, de esa forma, la norma no comporta una violación al principio non bis in idem, por lo cual se declarará su constitucionalidad, frente al cargo que ha sido analizado."

Resulta muy elocuente este planteamiento de la Corte Constitucional por cuanto pasa por alto que para afirmar que se ha matado "por culpa" es menester establecer la existencia de un nexo de determinación o imputación entre la violación del deber objetivo de cuidado y el resultado muerte, como es admitido de manera pacífica por la doctrina nacional| ${ }^{16}$. Por tanto, si la embriaguez o el influjo de aquellas otras sustancias sobre el organismo del sujeto activo deben haber sido determinantes del resultado, como lo señala la Corte, tal comprobación lo único que nos estaría indicando es, por una lado, que en ese caso concreto la violación al deber objetivo de cuidado consistió en actuar bajo el influjo del alcohol o de otras sustancias y por el otro, que entre esa infracción al deber de cuidado y el resultado hay un nexo de determinación y por tanto, en últimas, que se dan los presupuestos de tipo básico del homicidio imprudente.

16 Por todos, Cadavid Quintero, Alfonso, “El delito imprudente en el proyecto de reforma a la legislación penal", en Nuevo Foro Penal, No. 61, Bogotá, 1999, pp. 72-80. 
140 El homicidio imprudente agravado por la embriaguez o el influjo de sustancias que produzcan dependencia física o psíquica - Juan Oberto Sotomayor Acosta y Juan Carlos Álvarez Álvarez

De manera que si no se puede acreditar que la violación al deber de cuidado consistente en actuar bajo el estado de embriaguez haya sido determinante del resultado, lo que no hay es delito imprudente alguno. Por esta razón, la explicación que ofrece la Corte Constitucional para fundamentar su decisión en el sentido de que la agravante no vulnera el non bis in idem resulta insatisfactoria, puesto que la exigencia de que la embriaguez o el influjo de las sustancias que producen dependencia física o psíquica sea determinante en el resultado, lo que está indicando es precisamente que el fundamento del homicidio imprudente en ese caso concreto consiste en haber violado el deber de cuidado actuando en estado de embriaguez y por tanto, no se entiende por qué esa misma circunstancia se puede tomar al mismo tiempo como agravante, sin que ello implique desvalorar dos veces el mismo hecho.

De otra parte, y con una argumentación ya no referida al problema del non bis in idem sino a la fundamentación de la agravante basada en el mayor reproche que supuestamente se deriva del hecho de que el sujeto voluntariamente haya alterado sus condiciones psico-motrices, afirma también la Corte Constitucional:

"Cabe destacar que con la agravación de la pena no se tiene el propósito de "formular un reproche a la persona por el hecho mismo" del consumo, sino un aumento por la mayor censura que amerita no haber observado una conducta más cuidadosa, "pudiendo obrar de otro modo y poseyendo actitud psicofísica para comprender el hecho", pero a pesar de ello incurrir voluntariamente "en el comportamiento merecedor de reproche punitivo".

Como ya se dijo respecto de los planteamientos de Gómez Méndez ${ }^{17}$, en realidad lo que la Corte está aquí planteando es un supuesto de actio libera in causa y por tanto, se trata de un argumento que no da cuenta ni de un mayor injusto, ni de una mayor culpabilidad del hecho, sino de un reproche al autor por haberse puesto en el estado de alteración de sus capacidades psico-motrices en un momento anterior a la realización del hecho, que en todo caso tiene como único efecto el de posibilitar la valoración de la posible imprudencia del sujeto respecto de la conducta previa, la cual, como todas las acciones imprudentes, debe necesariamente voluntaria, pues de lo contrario no cabría hablar ni siquiera de la existencia de una acción que pueda ser objeto de valoración penal alguna. Para explicarlo con un ejemplo elemental: también la acción de quien conduce a exceso de velocidad (a consecuencia de lo cual mata a peatón) debe ser voluntaria para que de dicha acción pueda predicarse al menos culpa; luego, en definitiva, la voluntariedad de la conducta es también un requisito inherente a toda conducta imprudente y por tanto tampoco podría ello fundamentar su agravación.

17 Véase Gómez Méndez, Alfonso, Delitos contra la vida y la integridad personal, pp. 264-265. 
Por último, la Corte Constitucional también utiliza argumentos relativos a la culpabilidad para justificar la agravante, así:

"el fundamento de la circunstancia de agravación ahora analizada es el mayor riesgo generado cuando el agente se encuentra, por ejemplo bajo la influencia del alcohol en la conducción de automotores, donde se perturban, entre otras, la capacidad visual y los reflejos, dificultando la posibilidad de impedir el resultado, limitaciones sicomotoras también provocadas por el consumo de otras sustancias alucinógenas...".

Sobre este particular remitimos a las críticas formuladas a un planteamiento similar de un sector de la doctrina colombiana en vigencia del código penal de $1980^{18}$, las cuales ya han sido reseñadas en este trabajo y que en esencia se reducen a que no hay razones que hagan más reprochable, por ejemplo, conducir en estado de embriaguez que no acatar una señal de tránsito o conducir a exceso de velocidad.

A pesar a la objeciones a la citada sentencia de la Corte Constitucional, es claro que siendo dicho tribunal el órgano de cierre en materia constitucional y que sus sentencias de constitucionalidad tienen efectos vinculantes erga omnes, la decisión tomada por aquella en el sentido de que la circunstancia de agravación no es violatoria del non bis in ídem debe ser acogida por los operadores jurídicos en este aspecto concreto. Ello no significa que algunos de los problemas de interpretación de la circunstancia sigan teniendo relevancia e incluso puedan dar lugar a demandas de inconstitucionalidad o a inaplicación de la misma. Así, por ejemplo, la fundamentación basada en criterios de mayor culpabilidad sigue siendo problemática en la medida en que en últimas lo que conduce como ya se ha dicho anteriormente es a establecer supuestos de actio libera in causa con los problemas de inconstitucionalidad que ello plantearía. De igual forma, en relación con la culpabilidad sigue subsistiendo la contradicción valorativa que supone que esta sea a la vez circunstancia de agravación y de atenuación de la responsabilidad penal conforme a lo ya explicado.

Pero, además, los problemas de interpretación se acrecentaron con las reformas legales realizadas en los últimos años, en particular con las previsiones de la ley 1306 de 2009, cuyo análisis se realizará a continuación.

18 Cfr. Sotomayor Acosta, Juan Oberto y Gallego García, Gloria María, "Las circunstancias agravantes", pp. 39-45. 
142 El homicidio imprudente agravado por la embriaguez o el influjo de sustancias que produzcan dependencia física o psíquica - Juan Oberto Sotomayor Acosta y Juan Carlos Álvarez Álvarez

\section{Los problemas constitucionales que se derivan del tratamiento punitivo diferenciado de la circunstancia de la embriaguez a partir de la ley 1696 de 2013.}

a. El tratamiento jurídico-penal diferenciado de la embriaguez en el homicidio culposo (núms. 1 y 6 del art. 110 C.P.) conforme a las exigencias del derecho constitucional a la igualdad (arts. 13 Const. Pol. y 7 C.P.).

1) El tratamiento jurídico-penal diferenciado de los núms. 1 y 6 del art. 110 C.P.

La introducción de la agravante No. 6 del art. 110 ha generado una contradicción con la circunstancia del numeral 1 de dicho artículo: en el numeral 1 se agrava la pena de la mitad al doble, si el autor se encontraba "bajo el influjo de bebida embriagante o droga o sustancia que produzca dependencia física o síquica...". En el numeral 6 la agravación es de las dos terceras partes al doble (tanto de la pena principal como de la accesoria), si el autor "estuviese conduciendo vehículo automotor bajo el grado de alcoholemia igual o superior al grado $1^{\circ}$ o bajo el efecto de droga o sustancia que produzca dependencia física o síquica...".

Como puede apreciarse, se trata de dos circunstancias de agravación del homicidio culposo, que en esencia regulan lo mismo (homicidio culposo en estado de embriaguez o bajo el influjo de otras drogas que produzcan dependencia), cuyas notas diferenciales son las siguientes:

a) La agravante del núm. 1 en principio parece aplicable a cualquier homicidio culposo cometido en estado de embriaguez o bajo el influjo de otras drogas, mientras que la del núm. 6 se aplica sólo cuando además se realiza durante la conducción de vehículo automotor. Dado que en ambos casos se agrava la conducta cuando el autor ha cometido el hecho en estado de embriaguez o bajo el influjo de sustancias que produzcan dependencia física o síquica, pareciera configurarse un concurso de leyes, pues todos los eventos incluidos en el núm. 6 caben también en el núm. 1. No obstante, todo parece indicar que se trata de un concurso aparente de circunstancias agravantes, que bien podría resolverse recurriendo al criterio de especialidad ${ }^{19}$, toda vez que el núm. 6 es especial frente al 1, puesto que exige no sólo que el autor haya realizado el homicidio culposo en estado de embriaguez o bajo el influjo de otras drogas, sino, además, que lo hiciere conduciendo un vehículo automotor. De manera

19 Cfr. Velásouez, Fernando, Derecho penal, parte general, $3^{\text {a }}$ edición, Medellín, Comlibros, 2009, pp. 1006-1007: "cuando un supuesto de hecho reproduce los elementos típicos de otro más general y caracteriza de manera más precisa al hecho 0 al autor para añadirle elementos adicionales, es este el que toma en cuenta y no aquél". 
pues que desde este punto de vista el núm. 1 se aplicaría a todos los homicidios culposos en los que el autor haya actuado en estado de embriaguez o de drogas que produzcan dependencia física o síquica, salvo cuando el delito se hubiere cometido mediante la utilización de un vehículo automotor, evento éste que siempre habría que evaluar bajo las exigencias de la circunstancia del núm. 6 .

b) La agravante del núm. 1 no diferencia entre grados de embriaguez, por lo que su aplicación sólo presupone la existencia de embriaguez, lo cual según el art. 152 del Código Nacional de Tránsito Terrestre ocurre a partir de la presencia de 20 mg de etanol/100 ml de sangre total ${ }^{20}$. La aplicación del núm. 6, por el contrario, depende de que el grado de alcoholemia sea igual o superior al grado 1, esto es, de $40 \mathrm{mg}$ de etanol/100 ml de sangre total, en adelante.

c) La pena que el legislador ha previsto para la agravante del núm. 6 es mayor que la aplicable al núm. 1, puesto que en el primer caso el incremento de pena se inicia en las dos terceras partes de la mínima señalada para el homicidio culposo ${ }^{21}$, mientras que la del núm. 1 se inicia en la mitad.

d) Otra diferencia importante es que, en principio, el incremento punitivo del núm. 6 se aplica tanto a las penas principales (art. 35 C.P.) como accesorias (arts. 43 y 52 C.P.), mientras que el núm. 1 no alude a las penas accesorias, por lo que en principio debe entenderse referido sólo a las penas principales ${ }^{22}$.

Estas diferencias en la aplicación de ambas circunstancias pueden verse con claridad en el siguiente ejemplo:

Dos amigos, uno de ellos médico, se encuentran en un bar y consumen varias copas de licor. Mientras ello sucede el médico recibe una llamada del hospital en el que trabaja informándole que debe presentarse de inmediato porque se le requiere para una cirugía de urgencia. Su amigo se ofrece a llevarlo al hospital en su auto, pero en el camino, a consecuencia de su estado de embriaguez, atropella a un peatón causándole la muerte. El médico, al Ilegar al hospital inicia una delicada cirugía

20 Según el artículo 5 de la ley 1696 de 2013, que modificó el art. 152 de la Ley 769 de 2002 (Código Nacional de Tránsito Terrestre), los grados de alcoholemia que dan lugar a sanciones administrativas son cuatro: grado 0: entre 20 y $39 \mathrm{mg}$ de etanol/100 ml de sangre total; grado 1: entre 40 y $99 \mathrm{mg}$ de etanol/100 ml de sangre total; grado 2: entre 100 y $149 \mathrm{mg}$ de etanol/100ml de sangre total; grado 3: desde $150 \mathrm{mg}$ de etanol/100 mi de sangre total en adelante.

21 De acuerdo con los parámetros para la determinación de los mínimos y máximos de pena aplicables, previstos en el art. 60 C.P.

22 Podría pensarse que cuando en el núm. 6 se alude a la pena "accesoria" se está refiriendo a la pena de "privación del derecho a conducir vehículos automotores" consagrada en el inciso 2 del art. 109; no obstante, en este caso se trata de una pena principal y no accesoria, toda vez que como señala el art. 35 C.P., las penas privativas de otros derechos son penas principales cuando "como tal se consagren en la parte especial", que es precisamente lo que hace el art. 109 C.P. 
144 El homicidio imprudente agravado por la embriaguez o el influjo de sustancias que produzcan dependencia física o psíquica - Juan Oberto Sotomayor Acosta y Juan Carlos Álvarez Álvarez

que culmina con la muerte del paciente por un inadecuado procedimiento del médico, atribuible a su embriaguez. Ambos sujetos manifestaron luego que creyeron que las copas que había tomado no le impedían realizar de manera correcta dichas actividades.

Por consiguiente, conforme al ejemplo utilizado, la conducta del médico configura un homicidio culposo agravado por el núm. 1 del art. 110 C.P., independientemente del grado de su embriaguez y se le agravará "de la mitad al doble de la pena". El conductor, por su parte, deberá responder por un homicidio culposo agravado por el núm. 6 del mismo artículo, siempre y cuando la prueba de alcoholemia haya arrojado como resultado una embriaguez grado 1 en adelante; en este caso las penas (principales y accesorias) se agravarán "de las dos terceras partes al doble".

2) Los núms. 1 y 6 del art. 110 C.P. a la luz del derecho constitucional a la igualdad (arts. 13 Const. Pol. y 7 C.P.).

Conforme puede apreciarse, la regulación de la embriaguez como causa de agravación del homicidio culposo podría dar lugar a tensiones con el derecho a la igualdad recogido en el art. 13 de la Const. Pol., en los siguientes términos:

“Todas las personas nacen libres e iguales ante la ley, recibirán la misma protección y trato de las autoridades y gozarán de los mismos derechos, libertades y oportunidades sin ninguna discriminación por razones de sexo, raza, origen nacional o familiar, lengua, religión, opinión política o filosófica.

"El Estado promoverá las condiciones para que la igualdad sea real y efectiva y adoptará medidas en favor de grupos discriminados o marginados.

“El Estado protegerá especialmente a aquellas personas que por su condición económica, física o mental, se encuentren en circunstancia de debilidad manifiesta y sancionará los abusos o maltratos que contra ellas se cometan".

Tanto la doctrina ${ }^{23}$ como la jurisprudencia constitucional ${ }^{24}$ han entendido que

23 Cfr. Cepeda, Manuel José, Los derechos fundamentales en la Constitución de 1991, Bogotá, Temis, 1992; Bernal Pulido, Carlos, "El juicio de igualdad en la jurisprudencia de la Corte Constitucional", en el mismo, El Derecho de los derechos, Bogotá, Universidad Externado de Colombia, 2005, pp. 257 y ss.; Rodríguez Garavito, César A., "Derecho a la igualdad", en AAVV, Manual de Constitución y democracia. Volumen 1. De los derechos, $2^{\text {a }}$ edición, Bogotá, Universidad de los Andes, 2007, pp. 198-202; Quinche Ramírez, Manuel Fernando, Derecho constitucional colombiano. De la carta de 1991 y sus reformas, Bogotá, Temis, 2012, pp. 155-163.

24 Cfr., entre otras, las sentencias de la Corte Constitucional C-530 de 1993, C-022 de 1996, C-079 de 1999, C-093 de 2001. 
este art. 13 consagra no sólo la dimensión formal sino también la material del derecho a la igualdad, referidas, la primera, a que las personas que se encuentren en idénticas o similares circunstancias sean tratadas de manera igual, lo cual entraña entonces para las autoridades el deber de no discriminación; y la segunda, a que las personas que se encuentren en situaciones de desigualdad sean tratadas de manera diferenciada, lo que a su vez supone el correlativo deber estatal de promoción de las condiciones necesarias para que el logro de la igualdad sea real y efectiva. Conforme a la citada disposición, el derecho a la igualdad se concreta en cuatro mandatos fundamentales ${ }^{25}$ :

a) Un mandato de trato idéntico a destinatarios que se encuentren en circunstancias idénticas.

b) Un mandato de trato enteramente diferenciado a destinatarios cuyas situaciones no compartan ningún elemento común.

c) Un mandato de trato paritario a destinatarios cuyas situaciones presenten similitudes y diferencias, pero las similitudes sean más relevantes que las diferencias (trato igual a pesar de la diferencia).

d) Un mandato de trato diferenciado a destinatarios que se encuentren también en una posición en parte similar y en parte diversa, pero en cuyo caso, las diferencias sean más relevantes que las similitudes (trato diferente a pesar de la similitud).

En el caso de las agravantes por embriaguez del homicidio culposo se presentan tres situaciones problemáticas en relación con el derecho de igualdad, dos de los cuales podrían infringir el primero de los mandatos arriba enunciados, es decir, se trata de eventos en los que el legislador penal desconoce el mandato de trato idéntico a destinatarios que se encuentren en circunstancias idénticas, mientras que el otro tiene que ver es con el tercer mandato, esto es, se vulnera el mandato de trato paritario a destinatarios cuyas situaciones presenten similitudes y diferencias, pero en el que las similitudes son más relevantes que las diferencias (mandato de trato igual a pesar de la diferencia). Los tres son supuestos en los cuales, en definitiva, dos sujetos realizan el hecho en idénticas o parecidas circunstancias (es decir, en estado de embriaguez o bajo el influjo de sustancias que produzcan dependencia física o síquica), pero reciben por el homicidio culposo que cada uno comete un tratamiento punitivo diferente.

25 Cfr. Bernal Pulido, Carlos, "El juicio de igualdad...", p. 257. 
146 El homicidio imprudente agravado por la embriaguez o el influjo de sustancias que produzcan dependencia física o psíquica - Juan Oberto Sotomayor Acosta y Juan Carlos Álvarez Álvarez

Utilizando el ejemplo ya indicado, dicho tratamiento punitivo diferencial se hace evidente en los siguientes supuestos:

a) Cuando ambos sujetos actúan en estado de embriaguez grado 0 (20 a $39 \mathrm{mg}$ de etanol/100 m/ de sangre total).

Si tanto el médico como el conductor realizan el homicidio culposo en estado de embriaguez grado 0 (20 a $39 \mathrm{mg}$ de etanol/100 $\mathrm{ml}$ de sangre total), la pena sólo se agravará para el médico y no para el conductor. Ello tiene dos consecuencias importantes: por una parte, genera ámbitos punitivos muy diferentes, pues mientras para el médico la pena oscilaría entre 48 y 216 meses de prisión, para el conductor la pena sería de 32 a 108 meses. De otra parte, la distinta gravedad de la pena se traduce de igual manera en las posibilidades de acceder a la suspensión de la ejecución de la pena, pues las del médico (en quien concurre la agravante del núm. 1 del art. 110 C.P.) se encuentran supeditadas a que le sea impuesta la pena mínima, pues sólo en tal caso se cumpliría con el requisito objetivo del art. 63 de que la pena impuesta no sobrepase los cuatro años de prisión. Mientras que el conductor del vehículo tendría mayores posibilidades de acceder a dicho subrogado, toda vez que su pena empezaría en 32 meses. Es evidente en este caso que dos sujetos que realizan exactamente la misma conducta (homicidio culposo en estado de alcoholemia grado 0) reciben un tratamiento punitivo muy diferente por parte del legislador penal, por lo cual, como es obvio, se trata de sujetos que no gozan del mismo grado de libertad.

En principio habría, quizás, alguna manera de salvar esta objeción por vía de una interpretación conforme a la Constitución, pues a diferencia de lo que ocurre en los sistemas concentrados de control constitucional, donde una interpretación de este tipo tiene mayores limitaciones y se dificulta por ejemplo el recurso a interpretaciones "reconstructivas" 26 , ello es perfectamente posible en sistemas de control difuso o mixtos como el colombiano, donde es la propia carta fundamental la que le ordena a los jueces ordinarios que "En todo caso de incompatibilidad entre la Constitución y la ley u otra norma jurídica, se aplicarán las disposiciones constitucionales" (art. 4 Const. Pol.). Sin embargo, en materia penal debe tenerse

26 Cfr. al respecto, Ferreres Comella, Víctor, "El control de las leyes penales por parte de los jueces ordinarios", Mir Puig, Santiago y Corcoy Bidasolo (Dirs.); Hortal Ibarra, Juan Carlos, (Coord.), Constitución y sistema penal, Madrid, Marcial Pons, 2012, pp. 112-116. En opinión de Bernal Pulido, Carlos, "El principio de proporcionalidad de la legislación penal", en el mismo, El Derecho de los derechos, cit., p. 143, "'Parece plausible, por tanto, que cuando se advierta la inconstitucionalidad de una ley penal, ésta sólo sea declarada inexequible en los casos en que donde no sea posible su salvación por medio de una interpretación conforme con la Constitución". 
presente que toda interpretación encuentra un límite en la reserva absoluta de ley respecto de la creación de los delitos y de las penas, por lo que una interpretación conforme al texto constitucional no puede significar una extensión del ámbito de lo prohibido o mandado por la ley penal, o de la pena o medida de seguridad, más allá de lo establecido de manera taxativa y directa por el legislador ${ }^{27}$; por tanto, la posibilidad de interpretaciones "reconstructivas" sólo tiene cabida con criterios restrictivos, bien sea referida a la interpretación de la norma de conducta o de la norma de sanción.

En relación con el problema que se trata podrían plantearse dos alternativas de interpretación conforme a la Constitución: la primera sería la de entender que la ley 1696 de 2013, al hacer depender la relevancia agravante de la embriaguez en el homicidio culposo de la existencia de un determinado grado de alcoholemia, modificó también de forma tácita, en el mismo sentido, el núm. 1 del art. 110 C.P., es decir, que también en el núm. 1 la concurrencia de la circunstancia agravante se encontraría supeditada a la existencia en el autor de una embriaguez igual o superior a grado 1. Ello restablecería el trato igualitario que la Const. P. ordena, puesto que de esta manera, bien sea que el homicidio se cometa al conducir un vehículo automotor (evento que daría lugar a la aplicación de la agravante del núm. 6) o en un evento diferente (caso en el cual la aplicable es la agravante del núm. 1), siempre se exigiría el mismo grado de alcoholemia (grado 1 en adelante); por debajo de ello, por tanto, no habría lugar a la aplicación de la agravante en ninguno de los dos casos.

No obstante, esta posible interpretación, aunque en principio plausible, enfrentaría dos inconvenientes: el primero es que no logra superar del todo la existencia de una desigualdad de trato, pues si bien en tal caso el homicidio culposo sólo se agravaría cuando se trate de una embriaguez grado 1 en adelante, el problema ahora es que no se agrava en la misma proporción, con lo cual persiste el tratamiento desigual. Adicionalmente, esta interpretación se enfrenta también a otro problema de particular relevancia, que tiene que ver con la imposibilidad práctica de realizar una prueba de alcoholemia en supuestos diferentes a los de la seguridad vial. En efecto, hasta antes de la entrada en vigencia de la ley 1696 de 2013 la agravante del núm. 1 del art. 110 C.P. se entendía referida sólo a la existencia de embriaguez, razón por la cual se trataba de una circunstancia que bien podía probarse a través de cualquier medio probatorio; por supuesto, ello siempre ha sido más fácil cuando se trata de accidentes de tránsito, por cuanto la intervención de la policía facilita la prueba en dichos casos; pero ello no significaba que en otros 
contextos la existencia de embriaguez no pudiera probarse a través de testigos, vídeos, entre otros. No obstante, cuando ya no se trata sólo de probar la existencia de embriaguez sino de una alcoholemia grado 1 en adelante, se está exigiendo de manera necesaria la realización -independientemente del medio que se utilice para ello- de una prueba de alcoholemia, que la mayoría de las veces sería prácticamente imposible en contextos diferentes a los del tránsito vial. Piénsese en el caso del médico que realiza la cirugía en estado de embriaguez, en quien manipula un arma de fuego o una máquina peligrosa, en quien corta imprudentemente un árbol, etc. En estos casos a lo mejor podría establecerse que la persona se encontraba en estado de embriaguez, pero no que tenía 40 mg o más de etanol/100 ml de sangre total; en la práctica ello significaría que sólo se agravarían las penas por embriaguez en el supuesto del núm. 6. Por tanto, esta interpretación no resuelve los problemas de constitucionalidad de la reforma al art. 110 C.P. introducida por la ley 1696 de 2013, dado que desde el punto de vista constitucional sería inadmisible que el legislador establezca como agravante de un delito un hecho que no puede constatarse, o que sólo lo sería en casos excepcionales, puesto que ello redundaría en un incremento de la inseguridad jurídica, pues la mayor responsabilidad penal no dependería ya de ley y ni siquiera de una adecuada investigación judicial, sino de circunstancias totalmente aleatorias.

La otra posible manera de salvar la objeción constitucional, dada la inviabilidad de la anterior, sería la de entender que la embriaguez es siempre causal de agravación del homicidio culposo en accidentes de tránsito, pero que debe diferenciarse según el grado de alcoholemia: si concurre una embriaguez grado 0 lesto es, de 20 a $39 \mathrm{mg}$ de etanol/100 $\mathrm{ml}$ de sangre total), el autor queda sometido a la agravante general por embriaguez del núm. 1; y si la embriaguez es grado 1 (40 o más mg de etanol/100 ml de sangre total) en adelante, la aplicable es la agravante del núm. 6. Pero esta interpretación tampoco está exenta de obstáculos, el primero de los cuales tiene que ver con el hecho de que, como dijo atrás, existió una clara voluntad de legislador de regular mediante la ley 1696 de 2013 todos los eventos de embriaguez en el tránsito vial; y producto de esa intención introdujo el grado de alcoholemia como criterio de evaluación de la relevancia de dicha circunstancia respecto de un homicidio culposo y estableció con claridad que en los eventos de conducción de automotores la relevancia agravante de la embriaguez comienza a partir del grado 1. Por tanto, agravar un homicidio culposo en estado de embriaguez inferior a grado 1, cuando se conduce un vehículo automotor, iría claramente en contravía de lo regulado de manera expresa por la mencionada ley y de la intención misma del 
legislador, al tiempo que implica un abierto desconocimiento de la especialidad del núm. 6 respecto del núm. 1 del art. $110 \mathrm{CP}$.

Adicionalmente, tampoco una interpretación como ésta logra superar el problema del trato diferencial, pues, como se dijo antes, todavía faltaría por explicar por qué se sanciona con más pena el homicidio culposo en accidente de tránsito cuando el conductor se encontraba en estado de embriaguez grado 1 en adelante, en comparación con otros homicidios culposos cometidos en el mismo grado de embriaguez. Pero ello sitúa el análisis en el supuesto siguiente.

b) Cuando ambos sujetos actúan en estado de embriaguez igual o superior a grado 1 (40 $\mathrm{mg}$ de etanol/100 $\mathrm{ml}$ de sangre total, en adelante).

En el caso de que tanto el médico como el conductor realizan el homicidio culposo en estado de embriaguez grado 1 en adelante, esto es, cuando tienen 40 0 más $\mathrm{mg}$ de etanol/100 $\mathrm{ml}$ de sangre total, en ambos casos, como ya se dijo, se agrava la pena por embriaguez, aunque con consecuencias muy diferentes: en primer término existe una diferencia en cuanto al mínimo de la pena a imponer, pues para el médico el incremento empieza en la mitad de la pena mínima (16 meses) mientras que para el conductor el aumento punitivo se inicia en las dos terceras partes (es decir, en 21 meses y 10 días); ello significa que en los ejemplos citados, la pena para el conductor sería de 53 meses y 10 días a 216 meses de prisión, mientras que la del médico sería de 48 a 216 meses.

Lo anterior genera una consecuencia adicional de suma importancia, pues a diferencia de lo que ocurre en el supuesto analizado con anterioridad, en este, de imponerse la pena mínima sólo el médico tendría derecho a la suspensión condicional de la ejecución de la pena (art. 63 C.P.), puesto que para el caso del conductor la pena impuesta siempre excedería los cuatro años de prisión.

Otra diferencia de trato la representa el hecho de que de imponerse como accesoria una pena privativa de otros derechos, dicha pena debería agravarse sólo cuando concurre el núm. 6. De conformidad con los ejemplos propuestos ello significaría que si en ambos casos el juez considera plausible la imposición de una pena accesoria, como podría ser v. gr. la de "prohibición de consumir bebidas alcohólicas 0 sustancias estupefacientes o psicotrópicas" (art. 43-8 C.P) ${ }^{28}$, dicha

28 Como sería perfectamente posible conforme a las reglas de imposición de las penas accesorias previstas en el art. 52 C.P., cuyo inciso 1 establece que "Las penas privativas de otros derechos, que pueden imponerse como principales, serán accesorias y las impondrá el juez cuando tengan relación directa con la realización de la conducta punible, por haber abusado de ellos o haber facilitado su 
pena se incrementaría en la proporción fijada por el núm. 6 para el caso del conductor, pero en el caso del médico dicho incremento no tendría lugar.

Los problemas antes mencionados no parecen posibles de resolver mediante una interpretación conforme a la Constitución como las planteadas en el supuesto anterior, toda vez que en este caso la solución de las desigualdades anotadas sólo sería posible extendiendo la agravante del núm. 6 a todos los homicidios culposos en estado de embriaguez grado 1 en adelante, lo cual supondría una flagrante violación del principio de legalidad penal, pues lo que el legislador decidió fue la aplicación del núm. 6 única y exclusivamente a los supuestos en los que se utilizó un vehículo automotor; se trataría, por tanto, de una indebida extensión de la pena a eventos no previstos por el legislador.

c) Cuando un sujeto realiza el hecho conduciendo un vehículo automotor en estado de embriaguez grado 0 y otro lo hace bajo el influjo de sustancias que generan dependencia física o síquica.

Cuando ambos sujetos han realizado el hecho bajo el influjo de sustancias que generan dependencia física o síquica no se generan mayores problemas, puesto que en ambos supuestos procede la agravante: la del núm. 1 en el caso del médico y la del núm. 6 en el del conductor. El posible problema radica sólo en relación con la aplicación del núm. 6, puesto que a diferencia de lo que ocurre con la embriaguez por alcohol, en la que se exige un mínimo de $40 \mathrm{mg}$ de etanol/100 $\mathrm{ml}$ de sangre total, la agravación por el consumo de sustancias estupefacientes y psicoactivas no depende de ningún grado de intoxicación. Luego, si el conductor del ejemplo conducía el vehículo después de haber ingerido dos copas de aguardiente y el examen de alcoholemia dio de 20 a 39 mg de etanol, no hay lugar a la aplicación de ninguna agravante, como ya se dijo; no obstante, si ese mismo conductor en vez de las dos copas de aguardiente consumió un cigarrillo de marihuana, podría imponerse ya la circunstancia agravante, puesto que en tal caso su aplicación no depende de ningún grado de intoxicación. En este supuesto no se está frente a situaciones propiamente idénticas, pues en una se consume una bebida alcohólica (aguardiente) y en la otra una sustancia psicoactiva (marihuana), pero sí ante situaciones muy similares, hasta el punto que el legislador las trata a ambas como agravantes del homicidio imprudente. Sin embargo, no existen evidencias que respalden la tesis del legislador de que es más grave para la seguridad colectiva y la vida de las demás

comisión, o cuando la restricción del derecho contribuya a la prevención de conductas similares a la que fue objeto de condena". 
personas conducir un vehículo automotor después de consumir un cigarrillo de marihuana que después de haber consumido dos copas de aguardiente.

3) Las agravantes 1 y 6 del art. 110 C.P.: una cuestión de constitucionalidad.

Todas estas diferencias en el tratamiento legal de situaciones prácticamente idénticas, no parecen generar dudas respecto de la existencia de una intervención prima facie en el derecho a la igualdad, que amerita entonces su evaluación desde el punto de vista constitucional, pues de manera evidente se tratan de forma desigual a varios destinatarios del derecho y ello sólo es constitucionalmente admisible cuando hay razones que lo justifiquen ${ }^{29}$, pues, como ha dicho la Corte Constitucional, "Si no hay ninguna razón suficiente para la permisión de un tratamiento desigual, entonces está ordenado un tratamiento igual ${ }^{30 " .}$. Luego, el problema a resolver es el de si existen en este caso razones suficientes que justifiquen este tratamiento diferencial.

En principio podría pensarse que las contradicciones ya expuestas son tan evidentes como insuperables y que, por tanto, lo dicho es suficiente para afirmar la contradicción del núm. 6 del art. 110 C.P. con el derecho constitucional a la igualdad, pues no parece plausible que a efectos del merecimiento de pena puedan establecerse diferencias, por ejemplo, entre quien mata a otro imprudentemente al conducir su automóvil después de consumir dos copas de aguardiente y quien hace lo mismo después de consumir un cigarrillo de marihuana; como tampoco parece existir una mayor responsabilidad penal en quien conduce un vehículo en estado de embriaguez en comparación con la del médico que en el mismo estado de embriaguez realiza una cirugía o en la del operario que en estado de embriaguez manipula una máquina peligrosa, etc.

Pese a lo anterior, debe reconocerse que la prohibición de discriminación y el deber de promoción inherentes al derecho a la igualdad son normativamente indeterminados, pues la norma que los consagra (art. 13 Const. Pol.) no establece con precisión cuándo un trato diferente de varios destinatarios está prohibido, es posible 0 es obligatorio, desde el punto de vista constitucional ${ }^{31}$. Luego, podría pensarse que

29 Bernal Pulido, Carlos, "El juicio de igualdad", pp. 257-262; Rodríguez Garavito, César A., "Derecho a la igualdad", pp. 198-202; Quinche Ramírez, Manuel Fernando, Derecho constitucional colombiano, pp. 155-163. Con carácter general sobre la estructura del derecho a la igualdad, AleXY, RoBert, Teoría de Ios derechos fundamentales, Madrid, Centro de Estudios Constitucionales, 1997, pp. 381-418, en especial, pp. 395-398.

30 Corte Constitucional, sentencia C-022 de 1996, p. 8.

31 Cfr. Bernal Pulido, Carlos, "El juicio de igualdad", p. 259. 
precisamente dicha vaguedad normativa hace de la determinación de los criterios de diferenciación admisible un asunto de competencia prevalente del legislador, sobre todo cuando, como es el caso, no se está en presencia de la utilización de criterios "sospechosos de diferenciación" o "potencialmente discriminatorios"32, como son aquellos a los que de manera expresa se refiere la Constitución en el art. 13 (esto es, el "sexo, raza, origen nacional o familiar, lengua, religión, opinión política o filosófica") y en otros artículos. Con mayor razón si se está ante un asunto de naturaleza penal, ámbito en el cual suele reconocérsele al legislador un amplio poder de configuración, que ha significado en esta materia la aplicación de un debilísimo test de igualdad y en general un muy poco exigente control constitucional de las leyes penales por parte de la Corte Constitucional ${ }^{33}$.

En efecto, podría argumentarse que no existiendo dudas respecto de la legitimidad de la prevención de los delitos -y en particular del homicidio imprudente en accidentes de tránsito- como fin a alcanzar por parte del Estado, el legislador tiene libertad para seleccionar los instrumentos que considere más adecuados para ello, y al no existir una manera prestablecida de alcanzar dicho fin, se trataría de un asunto que cabe resolver conforme a las opciones ideológicas y políticas mayoritarias (principio democrático). Conforme a ello se podría entonces argumentar que dentro de las competencias constitucionales del legislador cabe perfectamente la posibilidad de diferenciar, con fines de prevención, el tratamiento de la embriaguez en el ámbito del tránsito vial respecto de otros ámbitos de la vida social.

Como ha señalado la Corte Constitucional de manera reiterada:

32 Véase, Corte Constitucional, sentencia C-093 de 2001, p. 23; Bernal Pulido, Carlos, "El juicio de igualdad", p. 267.

33 La gradación del escrutinio de igualdad en "escrutinio débil", "escrutinio estricto" y "escrutinio intermedio", que tiene su origen en la jurisprudencia de la Corte Suprema de Justicia de los Estados Unidos (sobre el particular, Bernal Pulido, Carlos, "El juicio de igualdad”, pp. 266-271), ha sido utilizada también por la Corte Constitucional colombiana (por ejemplo, en las sentencias C-265 de 1994, C-093 de 2001 y C-673 de 2001). Sobre la debilidad del control constitucional de las leyes penales en Colombia, cfr., Lopera Mesa, Gloria Patricia, "El principio de proporcionalidad en el control de constitucionalidad de leyes penales sustantivas (una aproximación a su empleo en la jurisprudencia constitucional colombiana), en Nuevo Foro Penal, No. 67, Medellín, 2005, pp. 22 y ss.; así también lo destaca Ferreres Comella, Víctor, "El control de las leyes penales...", p. 115, en relación con el Tribunal Constitucional español. Sobre los distintos niveles de intensidad del control de constitucionalidad y una muy fundamentada propuesta de un control exigente de control de constitucionalidad de las leyes penales, Lopera Mesa, Gloria Patricia, Principio de proporcionalidad y ley penal. Bases para un modelo de control de constitucionalidad de las leyes penales, Madrid, Centro de Estudios Políticos y Constitucionales, 2006, pp. 553-607. 
“... para la definición de la política criminal del Estado y, en particular, en materia penal para la configuración de las conductas punibles, el órgano legislativo tiene una competencia amplia y exclusiva que encuentra claro respaldo en el principio democrático y en la soberanía popular (C.P. arts. $1^{0}$ y $3^{\circ}$ ), razón por la cual, corresponde a las mayorías políticas, representadas en el Congreso, determinar, dentro de los marcos de la Constitución Política, la orientación del Estado en estas materias" ${ }^{\prime 34}$.

En igual sentido, en la sentencia C-575 de 2009, dijo la Corte Constitucional:

“... el legislador cuenta con una amplia libertad de configuración para determinar cuales conductas han de ser consideradas punibles así como para fijar las penas correspondientes a tales comportamiento, también puede incluir agravantes 0 atenuantes de la sanción, puede delimitar el ámbito de responsabilidad del sujeto o establecer causales de exclusión de antijuridicidad o de irresponsabilidad, puede definir los procedimientos exigibles para la imposición de las penas y puede determinar las formas de redención de la misma, entre muchos otros aspectos" ${ }^{\prime \prime}$.

No obstante, con la misma claridad que la Corte Constitucional ha defendido los amplios poderes de configuración del legislador penal, también ha reiterado que no se trata de un poder ilimitado, toda vez que la misma Constitución fija unos límites al ejercicio del poder penal estatal:

“Con todo, el ordenamiento jurídico colombiano está fundado, entre otros, en el principio de proscripción de la arbitrariedad, que compromete a las autoridades públicas con la satisfacción de los intereses sociales y la realización del orden justo mediante la expedición de actos legítimos, razonables y proporcionales. En el terreno penal, implica que la libre potestad de configuración sólo se ejerce legítimamente cuando las disposiciones encaminadas a sancionar el delito son proporcionales y se enmarcan en el respeto de los derechos y garantías consagrados en la Carta Política.

“En esa medida si bien la Constitución es el origen de la libertad de configuración del legislador en materia penal, a su vez obra como un límite a esa misma potestad"36.

34 Corte Constitucional, sentencia C-226 de 2002, p. 14.

35 Corte Constitucional, sentencia C-575 de 2009, p. 28, con referencias a otras sentencias en el mismo sentido.

36 Corte Constitucional, sentencia C-575 de 2009, pp. 28-29, cursivas añadidas. En el mismo sentido, en la sentencia C-1404 de 2000, la Corte Constitucional había dicho: "En principio, por virtud de la cláusula general de competencia legislativa que le atribuyen los artículos 114 y 150 de la Carta, el Congreso cuenta con la potestad genérica de desarrollar la Constitución a través de la creación de normas legales; ello incluye, por supuesto, la facultad de legislar sobre cuestiones penales y penitenciarias. No obstante, como lo ha reconocido ampliamente esta Corporación, dicha libertad de configuración del legislador encuentra ciertos límites indiscutibles en la Constitución, la cual no le 
154 El homicidio imprudente agravado por la embriaguez o el influjo de sustancias que produzcan dependencia física o psíquica - Juan Oberto Sotomayor Acosta y Juan Carlos Álvarez Álvarez

El problema en el caso del derecho a la igualdad de trato es que al no estar establecidos de forma clara y taxativa los supuestos que constituyen una diferenciación prohibida, no es fácil llegar a un juicio definitivo acerca de hasta donde la Constitución le permite diferenciar al legislador en su objetivo de prevención de los delitos. Por esta razón se admite que en estos casos lo que rige para el legislador es más bien una prohibición de exceso, esto es, de intervenciones desproporcionadas y por ende arbitrarias ${ }^{37}$, para cuya determinación suele recurrirse al denominado test o principio de proporcionalidad, por tratarse de una estructura de argumentación que pretende conciliar "el respeto a la libertad de configuración del legislador con un control material de sus decisiones que procure la máxima efectividad de los derechos fundamentales" ${ }^{\prime \prime}$.

b. La circunstancia agravante del núm. 6 del art. 110 C.P. (introducida por la ley 1696 de 2013): una medida desproporcionada y por tanto inconstitucional.

El principio de proporcionalidad supone el enjuiciamiento de la ley (en este caso el núm. 6 del art. 110 C.P.) desde el punto de vista de los subprincipios de idoneidad, necesidad y proporcionalidad en sentido estricto ${ }^{39}$, análisis que en todo caso presupone la legitimidad constitucional del fin a alcanzar con dicha ley. En el caso de las leyes penales este fin suele entenderse referido a la prevención de

permite actuar arbitrariamente, sino de conformidad con los parámetros que ella misma establece. Es decir, se trata de una potestad suficientemente amplia, pero no por ello ilimitada; y en materia penal y penitenciaria, estos límites son particularmente claros, por estar de por medio derechos fundamentales muy caros para la persona humana, como lo son la libertad personal y el debido proceso, así como valores sociales tan importantes como la represión del delito o la resocialización efectiva de sus autores".

37 Cfr. Corte Constitucional, entre otras, las sentencias C-022 de 1996, C-1404 de 2000, C-093 de 2001, C-673 de 2001, C-226 de 2002, C-575 de 2009.

38 Lopera Mesa, Gloria Patricia, "Principio de proporcionalidad y control constitucional de las leyes penales", en Jueces para la Democracia, No. 53, Madrid, 2005, p. 50. Sobre la utilización del principio de proporcionalidad en la jurisprudencia de la Corte Constitucional colombiana, y en particular en relación con el juicio constitucional de igualdad, Bernal Pulido, CARLOS, "El juicio de igualdad", pp. 274279; en igual sentido, Rodríguez Garavito, César A., “Derecho a la igualdad”, pp. 198-202. En particular se destacan las sentencias C-022 de 1996 y C-093 de 2001; en materia penal, entre las recientes, es particularmente relevante la sentencia C-575 de 2009.

39 Cfr. ampliamente sobre el particular y con carácter general, Bernal Pulido, Carlos, El principio de proporcionalidad y los derechos fundamentales, Madrid, Centro de Estudios Políticos y Constitucionales, 2005, pp. 688 y ss.; su aplicación en el juicio de constitucionalidad de las leyes penales, en Lopera Mesa, Gloria Patricia, Principio de proporcionalidad y ley penal, pp. 387 y ss.; la misma, "Principio de proporcionalidad y control constitucional...", pp. 41-47. 
lesiones o peligros para los bienes jurídicos ${ }^{40}$, aspecto sobre el cual no podría haber dudas en el tema que aquí se trata, pues la legitimidad del fin perseguido por la circunstancia agravante prevista en el núm. 6 del art. 110 C.P., cual es la prevención de los homicidios imprudentes cometidos a través de la utilización de un vehículo automotor, se encuentra fuera de toda duda. El objetivo, pues, es la protección de un bien jurídico fundamental y de innegable relevancia constitucional (art. 11 Const. Pol.); lo que procede evaluar es si el medio elegido por el legislador para el logro de dicho fin es un medio idóneo, necesario y proporcional.

\section{1) Idoneidad}

En relación con el juicio de idoneidad son dos los aspectos a considerar ${ }^{41}$ : por una parte, la idoneidad de la norma de conducta, que en este caso es la circunstancia agravante consistente en la realización del homicidio culposo cuando "el agente estuviese conduciendo vehículo automotor bajo el grado de alcoholemia igual 0 superior al grado $1^{\circ} \mathrm{o}$ bajo el efecto de droga o sustancia que produzca dependencia física o síquica". Y de otra parte, habría que considerar igualmente la idoneidad de la norma de sanción, que consiste en el incremento de la pena del homicidio culposo "en las dos terceras partes al doble, en la pena principal y accesoria".

Tiene razón Lopera Mesa cuando entiende que el margen de control de que dispone el juez constitucional en relación con el juicio de idoneidad de las leyes penales es bastante reducido, por cuanto lo conveniente es empezar el juicio de proporcionalidad con un control débil en esta materia, que no impida desde un comienzo la evaluación de otras posibles razones a favor de la constitucionalidad de una ley ${ }^{42}$. En este sentido, la inidoneidad de una ley penal sólo sería admisible, por una parte, si se verifica que el pronóstico de peligrosidad objetiva de la acción realizado

40 Cfr. Lopera Mesa, Gloria Patricia, Principio de proporcionalidad y ley penal, pp. 326-385, en especial, pp. 341-370; para esta autora, al igual que para Prieto SAnCHís, Luis, "Una perspectiva normativa sobre el bien jurídico", Nuevo Foro Penal, No. 61, Medellín, 2003, pp. 61 y ss, el juicio sobre la existencia de un bien jurídico se encuentra integrado al principio de proporcionalidad. No obstante, parece ser más bien un presupuesto del mismo, es decir, un límite político criminal previo y autónomo: sin un bien jurídico no está legitimada constitucionalmente ninguna intervención penal; cfr. en este sentido a Roxin, CLAus, "¿Es la protección de bienes jurídicos una finalidad del Derecho penal?", en el mismo, Fundamentos político-criminales del Derecho penal, Buenos Aires, Hammurabi, 2008, pp. 115-140. Ahora, existiendo un bien jurídico que proteger, el principio de proporcionalidad lo que garantiza es que la protección del mismo no sea excesiva desde el punto de vista de la intervención sobre los derechos fundamentales de las personas.

41 Cfr. Lopera Mesa, Gloria Patricia, Principio de proporcionalidad y ley penal, pp. 395-432.

42 En tal sentido, Lopera Mesa, Gloria Patricia, Principio de proporcionalidad y ley penal, pp. 388-392. 
por el legislador al tipificar la conducta carece de respaldo en reglas de experiencia y en el conocimiento disponible; y, por otra, por la carencia de respaldo empírico por parte del legislador de que su intervención puede contribuir a la protección del bien jurídico o si logra acreditarse que se trata de una medida contraproducente con miras a dicha protección ${ }^{43}$.

Luego, salvo los casos extremos de tipos de peligro presunto ${ }^{44}$, la mayoría de las veces los tipos penales pueden satisfacer estas exigencias. No obstante, debe tenerse presente que cuando se trata -como en este caso- de una circunstancia agravante, dicho juicio de idoneidad no se satisface con la mera referencia a la idoneidad del tipo básico, pues no es éste el enjuiciado sino la circunstancia que lo agrava. Por tanto, la evaluación de la idoneidad de una circunstancia agravante debe empezar por su distinción de los elementos del delito, pues mientras estos últimos fundamentan el merecimiento de pena, las primeras simplemente lo gradúan. Por esta razón, toda circunstancia agravante presupone necesariamente la realización de los elementos constitutivos de la conducta punible y por tanto su contenido no debe coincidir en todo o en parte con los mismos, pues ello entrañaría una doble desvaloración jurídica del hecho, vale decir, como elemento del delito y como circunstancia agravante ${ }^{45}$. Y si dicho merecimiento de pena requiere siempre un hecho antijurídico (injusto) y la culpabilidad del sujeto, la mayor pena que introduce una circunstancia agravante sólo puede legítimamente estar fundamentada, a su vez, en la existencia de un mayor merecimiento de pena, esto es, en un mayor grado de injusto 0 un mayor grado de culpabilidad ${ }^{46}$.

43 Cfr. Lopera Mesa, Glokia Patricia, "Principio de proporcionalidad y control constitucional...", pp. 41-42.

44 Entendiendo por tales los basados en una valoración estadística por parte del legislador, que excluiría la valoración de la peligrosidad de la conducta por parte del juzgador en el caso concreto. Sobre la ilegitimidad de esta clase de tipos de peligro, cfr. Terradillos Basoco, Juan, "Peligro abstracto y garantías penales", en Nuevo Foro Penal, No. 62, Medellín, 1999, p. 74; y Schünemann, Bernd, "Protección de bienes jurídicos, ultima ratio y victimodogmática. Sobre los límites inviolables del derecho penal de un Estado de Derecho liberal”, en von Hirsch, Andrew, Seelmann, Kurt, Wohlers (ed. alemana); Robles Planas, Ricardo (ed. española), Límites al Derecho penal. Principios operativos en la fundamentación del castigo, Barcelona, Atelier, 2012, pp. 75-76.

45 Al respecto, Sotomayor Acosta, Juan Oberto y Gallego García, Gloria María, "Las circunstancias agravantes", pp. 38-39; y Tamayo Patiño, Francisco Javier, cit. 2012, pp. 48-49.

46 Existen no obstante muy buenas razones para entender que la culpabilidad no puede agravar la pena, pues como refiriéndose a la posición de Horn explica Luzón Peña, Diego Manuel, Lecciones de derecho penal, parte general, Valencia, Tirant lo Blanch, 2012, p. 510, “la culpabilidad opera únicamente como un filtro de la responsabilidad, gráficamente como un cedazo, que deja pasar más o menos injusto típico del hecho, atribuírselo al sujeto, porque toda la gravedad del desvalor del hecho está ya en el injusto típico y la culpabilidad, según sea plena, reducida o nula o, siguiendo con la imagen del 
En el caso del núm. 6 del art. 110, lo primero que llama la atención es que no se trata de una mera circunstancia agravante del homicidio culposo, sino en realidad de una circunstancia (realizar el hecho "conduciendo vehículo automotor bajo el grado de alcoholemia igual o superior al grado 1 o bajo el efecto de droga o sustancia que produzca dependencia física o síquica") que cualifica otra circunstancia agravante ya existente (la del núm 1: "encontrarse bajo el influjo de bebida embriagante 0 droga o sustancia que produzca dependencia física o síquica"). Como se vio antes, si resulta discutible que le embriaguez pueda justificarse como agravante del homicidio imprudente (en tanto dicha embriaguez es la que fundamenta precisamente la infracción al deber objetivo de cuidado inherente a todo delito culposo ${ }^{47}$ ), aún más difícil resulta justificar como más grave el hecho de quien comete el homicidio imprudente en estado de embriaguez conduciendo un vehículo automotor, que el de quien lo hace en el mismo grado de embriaguez pero en una actividad diferente. Volviendo al ejemplo atrás utilizado, sería preciso justificar que respecto de la protección de la vida de una persona es más riesgosa la conducta de quien conduce el vehículo en estado de embriaguez, que la del médico que realiza la cirugía en el mismo estado. Parece indiscutible que tanto conducir un vehículo automotor como realizar una cirugía son conductas permitidas aunque peligrosas, razón por la que se exige el cumplimiento de unos determinados deberes de cuidado; la realización de tales conductas en estado de embriaguez lo que hace es precisamente incrementar el riesgo de las mismas más allá de los niveles permitidos, sin que exista evidencia alguna que acredite que las consecuencias nocivas de la embriaguez o del uso de algunas sustancias prohibidas son mayores cuando la actividad consiste en la conducción de un vehículo automotor. Ello sería tanto como afirmar que cuando el médico del ejemplo conduce su vehículo en estado de embriaguez rumbo al hospital, realiza una conducta más grave que cuando luego al llegar al hospital realiza en el mismo estado de embriaguez una delicada cirugía.

cedazo, según que el espesor de malla y por tanto los huecos de la trama del cedazo sean amplios, estrechos o prácticamente cerrados, dejará pasar toda la gravedad del injusto, o sólo una parte 0 ninguna, pero la culpabilidad por sí misma no añade gravedad a la ya representada por el injusto típico; según esto, las agravantes, genéricas o específicas de algunos tipos, pertenecerán al injusto, suponer un mayor desvalor objetivo o subjetivo de la acción 0 un mayor desvalor del resultado, pero la culpabilidad no produce agravantes ni tipos agravados, sino sólo atenuación o exención". Este es el planteamiento que en Colombia asumen también Sotomayor Acosta, Juan Oberto y Gallego García, Gloria María, "Las circunstancias agravantes...", p. 39; y Tamayo Patiño, Francisco Javier, "Las circunstancias de agravación punitiva en el derecho penal colombiano...", pp. 50-52.

47 Sotomayor Acosta, Juan Oberto y Gallego García, Gloria María, "Las circunstancias agravantes...", pp. 41-45. 
Podría pensarse, no obstante, que dada la cantidad de muertes que se producen a consecuencia de la conducción de vehículos en estado de embriaguez, el legislador ha decidido intensificar la amenaza penal sobre los potenciales conductores ebrios, evento en el cual el análisis habría que referirlo a la idoneidad de la norma de sanción, en este caso, a la idoneidad de un mayor incremento punitivo como medio de prevención de dichos comportamientos. Desde este punto de vista, sin embargo, este incremento puede ser objetado por contraproducente y contradictorio. Contraproducente por cuanto el incremento es de tal magnitud que en algunos casos podría inclusive superar la pena de un homicidio doloso. Por ejemplo, si se interpreta de manera literal, lo que el núm. 6 del art. 110 C.P. dice es que la pena se aumentará de las dos terceras partes al doble, es decir, que el incremento (no la pena) va de las dos terceras partes al doble de la pena prevista para el homicidio culposo, lo que conduciría a una pena máxima de 324 meses (27 años) de prisión! Pero inclusive si en razón de la equívoca redacción se opta -como debe ser- por la interpretación más benigna, la pena máxima llegaría hasta los 216 meses de prisión, la cual de todas maneras sería superior a la pena mínima del homicidio doloso, que está fijada en 208 meses. Esta situación genera una contradicción valorativa evidente, pues significaría que sería posible la imposición de una pena más grave a un homicidio culposo que a uno doloso, por lo que el autor de un homicidio podría resultar mejor tratado cuando lo hace con intención de matar que cuando sólo ha infringido un deber de cuidado. Ello, antes que un medio idóneo de prevenir homicidios imprudentes sería una manera de fomentar homicidios dolosos, pues al sujeto "le daría igual" actuar de una manera o la otra.

La fundamentación de la agravante del núm. 6 en una mayor necesidad preventiva de pena resulta además contradictoria por otra razón, pues si lo que se pretende con dicha intensificación de la pena es disuadir el uso de vehículos automotores en estado de embriaguez, no se explica por qué cuando la embriaguez no alcanza los $40 \mathrm{mg}$ de etanol no se agrava la pena al conductor del vehículo automotor y sí a quien comete el homicidio en una actividad diferente.

Aún más, la idoneidad disuasiva de la circunstancia de embriaguez podría también cuestionarse teniendo en cuenta las condiciones necesarias para que el derecho penal tenga efectos sobre las elecciones conductuales del sujeto, que según Robinson ${ }^{48}$ son tres: a) Conocimiento y entendimiento por parte del delincuente potencial, directa 0 indirectamente, de las implicaciones que para él tiene la

48 Robinson, Paul H., Principios distributivos del Derecho penal. A quién debe sancionarse y en qué medida, Madrid, Marcial Pons, 2012, pp. 54-79. 
norma que pretende influirle. b) De ser conocidas, hacer uso de tal conocimiento al momento de tomar decisiones. c) De hacer uso de tal conocimiento, se requiere adicionalmente que el sujeto perciba los costos del incumplimiento como superiores a los beneficios de la conducta delictiva, de forma tal que le lleve a tomar la decisión de omitir la conducta delictiva.

Aunque es prácticamente imposible que un potencial homicida imprudente pueda diferenciar la influencia de la aplicación de las normas de Derecho penal de la del gran número de variables que influyen en cómo termina actuando finalmente el sujeto ${ }^{49}$, si imaginamos que en efecto entiende las implicaciones que la agravante en mención tiene para él, faltaría acreditar todavía que tal conocimiento es tenido en cuenta al momento de tomar la decisión de conducir o no un vehículo en estado de embriaguez. De acuerdo con Robinson, lo que "Ios científicos de la conducta que estudian los patrones que la gente sigue a la hora de tomar decisiones saben que poder demostrar que una persona tiene algún grado de conocimiento sobre varios hechos que podrían ser relevantes para una decisión no significa que esos hechos sean recordados y movilizados adecuadamente por quien decide. Mucho depende del contexto concreto en el que surge la necesidad de tomar una decisión o de las concretas interpretaciones que hace de los hechos que le resultan relevantes" ${ }^{\prime \prime 0}$. Luego, en muchas ocasiones la personalidad del sujeto y las circunstancias materiales funcionan como verdaderos obstáculos a la elección racional ${ }^{51}$, entre los cuales resulta de gran relevancia precisamente el consumo de alcohol y de sustancias psicoactivas, en tanto influyen en el estado mental (en sentido amplio) del sujeto; los efectos de tales sustancias en el organismo funcionan en consecuencia como un mecanismo que impide o por lo menos disminuye y en todo caso dificulta las posibilidades de que las normas que regulan la responsabilidad penal sean tenidas en cuenta por el sujeto en la toma de decisiones. Y precisamente por ello es que el derecho penal siempre ha reconocido en la embriaguez y el consumo de drogas sicoactivas en general un factor que puede llegar a disminuir o inclusive a excluir la culpabilidad ${ }^{52}$, mas no agravarla.

49 Según explica Robinson, Paul H., Principios distributivos del Derecho penal, pp. 56-57, "dadas las bajas tasas de detención y persecución... resulta muy irreal pensar que el delincuente potencial intuitivamente puede llevar a cabo un análisis de regresión múltiple para adivinar las normas de responsabilidad aplicables y su significado para él".

50 Robinson, Paul H., Principios distributivos del Derecho penal, p. 58.

51 Cfr. Robinson, Paul H., Principios distributivos del Derecho penal, pp. 57-61, en especial pp. 58-59.

52 Cfr. Agudelo Betancur, Nódier, Embriaguez y responsabilidad penal, pp. 115 y ss. y Muñoz Sánchez, 
Por lo visto, son tantas las contradicciones que genera la agravante que se analiza que es difícil que pueda superar inclusive un control débil de idoneidad. Ya se dijo, sin embargo, que siendo tan explícita la idea del legislador de acudir a esta agravante con fines preventivos, alguien podría pensar que siempre cabe la posibilidad así sea remota de que el incremento punitivo que supone el núm. 6 del art. 110 C.P. pueda producir algún efecto disuasorio en algún caso. Admitiendo dicha posibilidad, conviene proceder entonces al juicio de necesidad, pues por lo menos en el plano teórico podría ser posible que unas muy débiles razones de idoneidad pudieran ser compensadas luego, en alguna medida, por unas fuertes razones de necesidad.

\section{2) Necesidad}

El subprincipio de necesidad supone la comparación del núm. 6 del art. 110 con otros medios alternativos, para lo que se requiere acreditar, por una parte, que no existe otra alternativa de tipificación que sea igualmente idónea para la (mayor) protección del bien y al mismo tiempo menos lesiva para el derecho fundamental afectado; y por otra, si no existen medios extra-penales suficientemente aptos para lograr una mayor protección del bien jurídico y, en caso negativo, se requiere así mismo determinar que la clase y cuantía del incremento punitivo sea el mínimo necesario para cumplir con la finalidad preventiva ${ }^{53}$.

Desde el punto de vista de la existencia de alternativas a la tipificación cabe recordar que en este caso se trata de una conducta que no sólo ya se encuentra tipificada como delito (homicidio imprudente) sino también agravada (núm. 1 del art. 110 C.P.). En efecto, la existencia de un tipo penal (homicidio culposo) que recoge en su integridad la infracción al deber objetivo de cuidado que supone la conducción de un vehículo automotor infringiendo los deberes de cuidado, así como la de una circunstancia agravante consistente precisamente en realizar dicha conducta en estado de embriaguez o bajo los efectos del consumo de sustancias que producen dependencia física o psíquica, hacen muy difícil que el núm. 6 del art. 110 C.P. pueda entenderse como una medida realmente necesaria. Piénsese en el simple hecho de que antes de la introducción de dicha norma los eventos por ella regulados ya eran calificados por el código penal como homicidios culposos agravados (art. 110, núm. 1) e inclusive sancionados con una pena máxima igual

Juan, "Responsabilidad penal del drogodependiente", en Revista Electrónica de Ciencia Penal y Criminología, 16-03 (2014), pp. 7 y ss. 
(216 meses de prisión). Aún más, debe tenerse presente que la norma básica del homicidio culposo contiene una pena adicional para los eventos en los cuales la conducta se comete utilizando vehículos automotores, consistente en "la privación del derecho a conducir vehículos automotores y motocicletas" de tres a cinco años; luego, existe ya una mayor sanción del homicidio culposo cuando se utiliza vehículo automotor, por lo que también desde este punto de vista el núm. 6 parece innecesario a efectos preventivos. En fin, si la conducta ya está no sólo tipificada y agravada sino también más gravemente sancionada, la diferenciación con efectos agravantes del tratamiento de quienes realizan dicha conducta conduciendo vehículos automotores resulta sin duda innecesaria, pues no se erige ni siquiera en un costo a asumir con miras a una mayor protección del bien jurídico, sino en un mayor costo a cambio de la misma protección ya existente; aún más, desde el punto de vista del ámbito de mayor protección de la agravante, esto es, del número de supuestos incluidos en la misma, la agravante del núm. 6 lo que supone en realidad -en comparación con la del núm. 1- es una disminución de los eventos que gozan de dicha "mayor protección", pues excluye de los mismos los casos de embriaguez por debajo de los $40 \mathrm{mg}$ de etanol/100 $\mathrm{ml}$ de sangre total. En cambio lo que sí se aumentó de manera considerable fue el número de derechos afectados con dicha agravante, toda vez que a la afectación de la libertad general de actuar que supone toda intervención mediante una norma penal ${ }^{54}$, se le suma en este caso la del derecho a la igualdad de trato, tal como se analizó atrás.

Esta falta de necesidad es aún más evidente si se tiene en cuenta que en la búsqueda legítima de una mayor protección de la vida e integridad física de las personas en el ámbito de la circulación vial el Estado cuenta ya con instrumentos sancionatorios penales y extrapenales suficientemente idóneos para lograr dicho objetivo, sin los inconvenientes que supone la modificación de las reglas que componen el sistema de responsabilidad penal. En efecto, si el legislador creía necesario intensificar la protección de ciertos bienes jurídicos en el ámbito del tráfico automotor, debe seleccionar los instrumentos penales y/o extrapenales adecuados para ello, los cuales pueden ir desde la tipificación de conductas de peligro concreto con miras a la protección de la seguridad en el tráfico vial, hasta la implementación de medidas administrativas de muy diversa índole. Por supuesto la creación de delitos contra la seguridad en el tráfico automotor no puede entenderse legítima a priori, pues dependerá de que pueda superar también un juicio constitucional de idoneidad, necesidad y proporcionalidad, así como otros no menos importantes de

54 Cfr. Lopera Mesa, Gloria Patricia, Principio de proporcionalidad y ley penal, pp. 278-297. 
carácter político criminal55; lo que se quiere resaltar es que en tal caso sería posible la delimitación de la mayor protección que el legislador pretende alcanzar mediante la introducción de la norma de conducta, aunque se pueda discutir luego, sin duda, su necesidad y proporcionalidad en sentido estricto.

La agravante del núm. 6 del art. 110 debe considerarse innecesaria, además, por cuanto la misma ley 1696 de 2013 introdujo un severísimo sistema de sanciones administrativas para los conductores ebrios, que implica la imposición de sanciones por la conducción desde el grado 0 de embriaguez (20 a $39 \mathrm{mg}$ de etanol/100 ml de sangre total) en adelante, mediante sanciones tan graves como la de cancelación definitiva de la licencia de la conducción, 90 días de trabajo comunitario y multa de hasta el equivalente a 1140 salarios mínimos diarios legales vigentes. Luego, con un régimen de sanciones administrativas tan severo difícilmente podría considerarse necesario recurrir por razones preventivas a un incremento de 5 meses y 10 días de la pena mínima del homicidio culposo por embriaguez, que es en últimas, junto con el incremento de la pena accesoria, en lo que se concreta la mayor penalización que supone la agravante del núm. 6.

Si se mira desde el punto de vista de la prevención especial negativa, sin duda la sanción administrativa resulta mucho más efectiva, pues si una persona puede suponer un peligro por conducir en estado de embriaguez, la mejor manera de controlar dicho riesgo es privándole de manera temporal o definitiva de la licencia de conducción, por lo que sin duda en este caso la medida extrapenal es mucho más idónea desde el punto de vista preventivo. Y desde el punto de vista de la prevención general, difícilmente podría alegarse que una pena de 53 a 216 meses de prisión (núm. 6 del art. 110 C.P.) previene mucho más que otra de 48 a 216 meses de prisión

55 Cabe recordar que la fiscalía general de la nación desde un comienzo se opuso a la iniciativa de convertir en delito la conducción en estado de embriaguez. Entre otros motivos, el vicefiscal general Jorge Fernando Perdomo Torres dijo: “Sería catastrófico desde el punto de vista práctico, económico y de la política criminal. En 2012 se les impusieron 70.000 comparendos a personas sorprendidas conduciendo en estado de embriaguez, lo que significa que, si penalizamos esa conducta, implicaría hacer 70.000 audiencias de legalización de captura, 70.000 audiencias de imputación y 70.000 audiencias de medida de aseguramiento al año, y el sistema judicial colombiano no cuenta con esa infraestructura... Necesitaríamos aproximadamente 300 fiscales adicionales dedicados a la seguridad pública, 300 asistentes de fiscal y otros 300 investigadores. En Bogotá, según las estadísticas, en un fin de semana son sorprendidas 250 personas conduciendo en estado de embriaguez, y para poder judicializarlas necesitaríamos por lo menos tres edificios similares al complejo de Paloquemao. Es muy importante que la ciudadanía, el Gobierno y los parlamentarios tengan en cuenta que en tan sólo un año casi duplicaríamos la población carcelaria que existe actualmente en el país" (en http://www.elespectador.com/noticias/judicial/seria-catastroficoenviar-carcel-todos-los-conductores-articulo-439311, consultado el 12/10/2014). 
(núm. 1 del art. 110 C.P.). Esta ausencia de necesidad de la medida que se analiza se hace aún más patente si se tiene en cuenta no sólo que la conducción en estado de embriaguez ni siquiera representa la mayor causa de accidentes en el tránsito vial $^{56}$, sino que si se analizan las estadísticas al respecto de los últimos años no se evidencia un incremento considerable de las tasas de homicidios en accidentes de transito ${ }^{57}$, lo cual es una buena muestra de que la creación de nuevos tipos penales en esta materia es una medida claramente innecesaria con miras a la protección de la vida y la integridad física de las personas. Con ello se demuestra también algo que ya desde Beccaria se ha repetido con insistencia: la prevención no depende tanto de la gravedad de la sanción sino de la certeza de su aplicación ${ }^{58}$, con mayor razón cuando se trata de la seguridad vial, ámbito en el que sin duda la amenaza de una pena "no influye en el delincuente potencial con la inmediatez que lo hace el paso del coche patrulla"59.

Y si la necesidad se analiza desde el punto de vista de la prevención especial positiva, esto es, teniendo en cuenta las necesidades de readaptación social del

56 Según datos del Instituto Nacional de Medicina Legal, en 2012 la aparente embriaguez del conductor sólo fue la sexta causa de los accidentes que terminaron con resultado de muerte: "Según las circunstancias que rodearon los hechos y sin contar los 3.922 casos sin información, el 23,1 \% de las muertes por accidentes de transporte se produjeron por exceso de velocidad, el 18,8\%, por violación de otras normas de tránsito, y el 11,7\%, por violación de normas de tránsito para peatones", cfr. Forensis. Datos para la vida, Vol. 14, No. 1, Bogotá, 2013, p. 359.

57 Según datos del Instituto Nacional de Medicina Legal, la tasa de muertes en accidentes de tránsito en Colombia entre 2004 y 2013 se ha mantenido entre 12.10 (2004) y 13.21 (2012) por cada 100 mil habitantes; cfr., Forensis. Datos para la vida, Vol. 15, No. 1, Bogotá, 2014, p. 174. Luego de analizar la evolución de los datos que ofrece Medicina Legal, la conclusión de Velandia Montes, Rafael, "Inseguridad vial y política penal en Colombia", en Derecho Penal Contemporáneo, No. 45, Bogotá, 2013, p. 130, es que "en los últimos 12 años ha habido aumentos y disminuciones en la cantidad de heridos en choques de tráfico, pero la tendencia ha sido más hacia la aminoración que a su acrecimiento".

58 Cfr. Beccaria, C., De los delitos y de las penas, edición bilingüe al cuidado de P. Andrés liáñez, Madrid, Trotta, 2011, p. 201: “La certeza de un castigo, aun moderado, producirá siempre una impresión más honda que el temor de otro más terrible, unido a la esperanza de la impunidad; pues los males, incluso mínimos, cuando son ciertos, atemorizan siempre los ánimos humanos, y la esperanza, don celestial, que con frecuencia todo lo reemplaza, aleja siempre la idea de males mayores, especialmente cuando la impunidad, que la avaricia y la debilidad conceden a menudo, aumenta su fuerza".

59 Robinson, Paul H., Principios distributivos del Derecho penal, p. 56. Este autor señala que en algunos países las leyes de incrementos punitivos en el tráfico vial inicialmente por la campaña publicitaria y presencia policial producen una disminución de las infracciones, pero luego, "... ausente el considerable incremento en las probabilidades de detención y condena a consecuencia de los esfuerzos de la policía, los cambios en la formulación de la norma penal, que crearon penas más graves, no incrementaron el efecto disuasorio" (p. 82). 
delincuente, debe tenerse presente que dentro de las sanciones administrativas existentes se encuentra no sólo la de realizar trabajos en beneficios de la comunidad, la cual es una medida mucho menos excluyente y menos desintegradora que la prisión, sino también la de realización de cursos de capacitación y educación, sin duda mucho más idóneos que la simple amenaza penal o el encierro carcelario para lograr un cambio de la conducta individual en este campo.

Por lo visto, la agravante del núm. 6 del art. 110 C.P. es no sólo u instrumento inidóneo sino también innecesario con miras al logro de una mayor protección de la vida y la integridad física de las personas en el ámbito del tráfico vial, y por ello el uso de tal instrumento deviene desproporcionado, si se tienen en cuenta los costos que supone en términos de la afectación de los derechos a la libertad y muy particularmente del derecho que toda persona tiene a recibir un trato igualitario por parte de todas las autoridades, lo cual incluye, por supuesto, al legislador penal. Se trata por ello de una medida inconstitucional y por tanto inaplicable.

\section{Bibliografía}

Aradue Moreno, Diego, “Consideraciones sobre la actio libera in causa, Nuevo Foro Penal, núm. 66, Medellín, Universidad EAFIT, 2003.

Agudelo Betancur, Nódier, Embriaguez y responsabilidad penal, Medellín, Nuevo Foro, 2012.

Alexy, Robert, Teoría de los derechos fundamentales, Madrid, Centro de Estudios Constitucionales, 1997.

Beccaria, C., De los delitos y de las penas, edición bilingüe al cuidado de P. Andrés lbáñez, Madrid, Trotta, 2011.

Bernal Pulido, Carlos, El Derecho de los derechos, Bogotá, Universidad Externado de Colombia, 2005.

- "El juicio de igualdad en la jurisprudencia de la Corte Constitucional".

- "El principio de proporcionalidad de la legislación penal".

Bernal Pulido, Carlos, El principio de proporcionalidad y los derechos fundamentales, Madrid, Centro de Estudios Políticos y Constitucionales, 2005.

Cadavid Quintero, Alfonso, "El delito imprudente en el proyecto de reforma a la legislación penal", en Nuevo Foro Penal, No. 61, Bogotá, 1999

Cepeda, Manuel José, Los derechos fundamentales en la Constitución de 1991, Bogotá, TEMIS, 1992.

Ferrajolı, Luigl, Derecho y razón. Teoría del garantismo penal, Madrid, Trotta, 1989. 
Ferreres Comella, Víctor, "El control de las leyes penales por parte de los jueces ordinarios", Mir Puig, Santiago y Corcoy Bidasolo (Dirs.); Hortal Ibarra, Juan Carlos, (Coord.), Constitución y sistema penal, Madrid, Marcial Pons, 2012.

Gómez López, Jesús Orlando, El homicidio, t. II, Bogotá, Temis, 1997.

Gómez Méndez, Alfonso, Delitos contra la vida y la integridad personal, Bogotá, Universidad Externado de Colombia, 1998.

Lopera Mesa, Gloria Patricia, "El principio de proporcionalidad en el control de constitucionalidad de leyes penales sustantivas (una aproximación a su empleo en la jurisprudencia constitucional colombiana), en Nuevo Foro Penal, No. 67, Medellín, 2005.

Lopera Mesa, Gloria Patricia, "Principio de proporcionalidad y control constitucional de las leyes penales", en Jueces para la Democracia, No. 53, Madrid, 2005.

Lopera Mesa, Gloria Patricia, Principio de proporcionalidad y ley penal. Bases para un modelo de control de constitucionalidad de las leyes penales, Madrid, Centro de Estudios Políticos y Constitucionales, 2006.

Luzón Peña, Diego Manuel, Lecciones de derecho penal, parte general, Valencia, Tirant Io Blanch, 2012.

Molina Arrubla, Carlos Mario, Delitos contra la vida y la integridad personal, Medellín, Diké, 1995.

Muñoz Sánchez, Juan, "Responsabilidad penal del drogodependiente", en Revista Electrónica de Ciencia Penal y Criminología, 16-03 (2014).

Prieto Sanchís, Luis, "Una perspectiva normativa sobre el bien jurídico", Nuevo Foro Penal, No. 61, Medellín, 2003

Quinche Ramírez, Manuel Fernando, Derecho constitucional colombiano. De la carta de 1991 y sus reformas, Bogotá, Temis, 2012.

Robinson, Paul H., Principios distributivos del Derecho penal. A quién debe sancionarse y en qué medida, Madrid, Marcial Pons, 2012.

Rodríguez Garavito, César A., "Derecho a la igualdad”, en AAVV, Manual de Constitución y democracia. Volumen 1. De los derechos, $2^{a}$ edición, Bogotá, Universidad de los Andes, 2007.

Roxin, CLaus, "¿Es la protección de bienes jurídicos una finalidad del Derecho penal?", en el mismo, Fundamentos político-criminales del Derecho penal, Buenos Aires, Hammurabi, 2008. 
Schünemann, Bernd, "Protección de bienes jurídicos, ultima ratio y victimodogmática.

Sobre los límites inviolables del derecho penal de un Estado de Derecho liberal", en von Hirsch, Andrew, Seelmann, Kurt, Wohlers (ed. alemana); Robles Planas, Ricardo (ed. española), Límites al Derecho penal. Principios operativos en la fundamentación del castigo, Barcelona, Atelier, 2012.

Sotomayor Acosta, Juan Oberto y Gallego García, Gloria María, "Las circunstancias agravantes del homicidio imprudente en el Código penal colombiano", en Nuevo Foro Penal, No. 61, Bogotá, 1999.

Tamayo Patiño, Francisco Javier, "Las circunstancias de agravación punitiva en el derecho penal colombiano. Aproximaciones a una fundamentación", en Nuevo Foro Penal, No. 79, Medellín, 2012.

Terradillos Basoco, Juan, "Peligro abstracto y garantías penales", en Nuevo Foro Penal, No. 62, Medellín, 1999.

Velandia Montes, Rafael, "Inseguridad vial y política penal en Colombia”, en Derecho Penal Contemporáneo, No. 45, Bogotá, 2013.

Velásouez, Fernando, Derecho penal, parte general, 3ª edición, Medellín, Comlibros, 2009. 